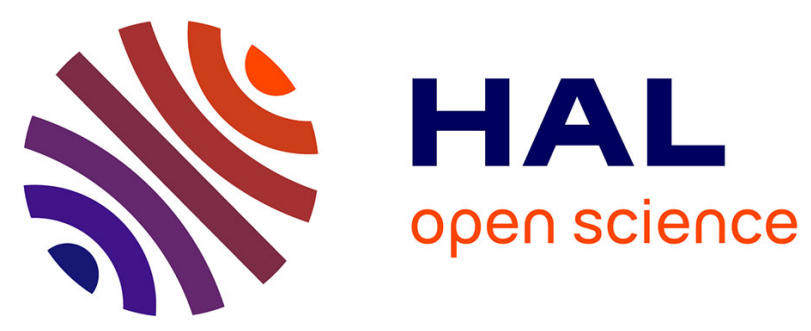

\title{
Prediction of thermal conductivity of liquid and vapor refrigerants for pure and their binary, ternary mixtures using artificial neural network
}

\author{
N. Ghalem, S. Hanini, Mx Naceur, M Laidi, Abdeltif Amrane
}

\section{- To cite this version:}

N. Ghalem, S. Hanini, Mx Naceur, M Laidi, Abdeltif Amrane. Prediction of thermal conductivity of liquid and vapor refrigerants for pure and their binary, ternary mixtures using artificial neural network. Thermophysics and Aeromechanics, 2019, 26 (4), pp.561-579. 10.1134/S0869864319040085. hal-02515141

HAL Id: hal-02515141

https://hal-univ-rennes1.archives-ouvertes.fr/hal-02515141

Submitted on 23 Mar 2020

HAL is a multi-disciplinary open access archive for the deposit and dissemination of scientific research documents, whether they are published or not. The documents may come from teaching and research institutions in France or abroad, or from public or private research centers.
L'archive ouverte pluridisciplinaire HAL, est destinée au dépôt et à la diffusion de documents scientifiques de niveau recherche, publiés ou non, émanant des établissements d'enseignement et de recherche français ou étrangers, des laboratoires publics ou privés. 


\section{Prediction of Thermal Conductivity of Liquid and Vapor Refrigerants for}

2 Pure and their Binary, Ternary Mixtures using Artificial Neural Network

3

N. Ghalem ${ }^{1}$, S. Hanini ${ }^{2}$, M. W. Naceur ${ }^{1}$, M.Laidi ${ }^{2}$, A. Amrane ${ }^{3} *$

${ }^{1}$ Département de Chimie Industrielle Université de Blida

²LBMPT, Université de Médéa, Quartier Ain D’Heb, 26000, Médéa, Algérie.

${ }^{3}$ Ecole Nationale Supérieure de Chimie de Rennes, Université de Rennes 1, CNRS, UMR 6226, 11 allée de Beaulieu, CS 50837, 35708 Rennes Cedex 7, France.

*Phone : +332232381 55; Fax : +33223 2380 99; email : abdeltif.amrane@univrennes1.fr

\section{Abstract}

The determination of thermophysical properties of hydrofluorocarbons $\left(\mathrm{HFC}_{\mathrm{S}}\right)$ isvery important,especially the thermal conductivity. The present work, investigated the potential of an artificial neural network (ANN) model to correlate the thermal conductivity of $\left(\mathrm{HFC}_{\mathrm{S}}\right)$ at (169.87-533.02) K, (0.047-68.201) MPa and (0.0089- 0.1984) W.m. ${ }^{-1} \mathrm{~K}^{-1}$ temperature, pressure and thermal conductivity ranges respectively, of 11systems from 3 different categories including five pure systems(R32, R125, R134a,R152a,R143a),four binary mixtures systems(R32+R125, R32+R134a, R125+ R134a,R125+R143a), and two ternary mixtures systems (R32+R125+ R134a, R125+ R134a+ R143a).Each one received 1817,794and 616 data points, respectively.The application of this model forthese3227 data points of liquid and vapor at several temperatures and pressures allowed to train, validate and test the model. This 
study showed that ANN models represent a good alternative to estimate the thermal conductivity of different refrigerant systems with a good accuracy. The squared correlation coefficients of thermal conductivity predicted by ANN were $\mathrm{R}^{2}=0.998$ with an acceptable level of accuracy of RMSE $=0.0035$ and $\mathrm{AAD}=0.002 \%$. The results of applying the trained neural network model to the test data indicate that the method has a highly significant prediction capability.

Key words: Refrigerant, Pure system, Mixtures, Thermal conductivity, Artificial Neural Network, Predictive model.

\section{Introduction}

In recent years, It has been highlighted the need to establish a balance between "energy consumption" and "environmental protection". The introduction of new refrigerants to replace Chlorofluorocarbons (CFCs)and Hydrochlorofluorocarbons(HCFCs) and the adaptation of new techniques should allow a reduction of the overall environmental impacts. To reduce security risks, another line of research has been developed towards the use of a secondary cooling loop (indirect cooling). The multiple processes used in industry are often based on heat exchanges.

Refrigerants cause global warming and ozone depletion bring on the environmental problems. So, UN drew up the Montreal Protocol(MP) and its London and Copenhagen Amendments[1]. Prior to the1980s, the principal classes of chemicals used as refrigerants in the refrigeration industry were CFCs and HCFCs. Based on growing evidence of ozone depleting potential (ODP)[2] of CFCs based on the Montreal Protocol, different industries turned to HCFCs as substitutes for CFCs. While HCFCs have a lower ODP than CFCs, they still damage the ozone layer and have become topic to scheduled period out by 2030, 
Hydrofluorocarbons (HFCs) were used as an acceptable alternative to CFCs and HCFCs because they possess several characteristics, including near-zero ODP and low Global warming potential (GWP), similarity to CFCs and HCFCs in physical properties, short atmospheric lifetimes, less or non-flammable and not expensive [3].

During the previous periods, owing to the understanding of the impact of refrigerants in the destruction of the ozone layer, the concepts of ozone depletion potentials (ODPs)[4]was designedto determine the relative capacity of a chemical to destroy ozone, $[5,6,7,8]$. Consequently, GWP is the purpose of several studies leading to the publication of a wide range of literature data [9].

Many researchers focused their efforts on the measurement of the thermophysical properties of these compounds (Refrigerants), aiming to find proper substitutes. Thermal conductivity is one of the major thermophysical properties, as defined by Fourier's equation, it is the ability of a material to transmit heat by means of conduction. Thermal conductivity, $\mathrm{K}\left(\mathrm{W} . \mathrm{m}^{-1} \mathrm{~K}^{-1}\right)$, is essential to theknowledge of heat transfer, in particular for refrigerants. In fact, the higher the liquid and vapor thermal conductivity, the higher the heat transfer coefficient.

The context of this work is related to the problem of the substitution of CFC and HCFCs. Experimental aspect (technical and measurements) and modeling aspects of the data obtained were first considered. The products studied are mixtures (pure, binary and ternary) compounds of R32, R125, R134a, R152a and R143a, which are HFCs of high interest to the industries of air conditioning and refrigeration.

Different authors have used diverse equations and methods to predict and reproduce the thermodynamic properties of refrigerant systems. Most of these attempts have been restricted to limited systems and to the best of the knowledge of no systematic work devoted to test the ability of these methods to predict the thermodynamic properties of different categories of systems is available. A number of theories are available providing equations to predict the 
thermal conductivity of liquids, these equations include theoretical calculations which consider intermolecular distances [10]; there are equations based on the theory of group contribution [11] or molecular descriptors [12,13]; equations involving some fixed parameters in order to describe the thermal conductivity [12,14]. An empirical approach based on a limited number of fixed physical parameters [15] was considered; a new equation to describe the thermal conductivity of R-32, R-125, R134a, and R-143a for practical use, applicable over a wide range of temperature and pressure has also been proposed [16]. Semi-empirical approaches for correlating thermal conductivity data for multicomponent liquid mixtures $[17,18]$ were studied, a method to estimate the thermal conductivity and the viscosity similar to cubic equations of state of halogenated hydrocarbon of pure substances in vapor and liquid regions $[19,20]$ was proposed; thermal conductivity modeling of refrigerant mixtures in a three-parameter corresponding states format [21] was carried out. There are an extensive studies have been published in the literature on the thermal conductivity of mixed refrigerants $[22,23,24]$ which suggested a correlation to calculate the thermal conductivity and viscosity of some alternative refrigerant mixtures such as R-507, R-404A, R-407C, and R-410A.

Recently, some researchers used artificial neural networks (ANNs) to correlate thermal conductivity property [25]:and obtained much better results than the traditional approach. To minimize the difficulties of experimental measurements and also their time-consuming and costly nature, it is desirable to develop predictive methods for estimating the phase behavior of these kinds of systems.

The purpose of this study was therefore the application of artificial neural network for representing/predicting the liquid and vapor thermal conductivity of pure refrigerants including R32, R125, R134a, R152a, R143a and their binary, ternary mixtures at different temperatures and pressures.

\section{Methodology and modeling}




\section{Neural network}

Artificial neural networks (ANNs) consist of a number of neurons working in unity to solve various scientific and engineering problems such as estimation of physical and chemical properties [26].ANN can operate like a black box model, which requires no detailed information about the system or equipment. The ANN can learn the relationship between input and output based on the training data.

ANNs have been used in many engineering applications such as control systems, in classification and in modeling complex process transformations. Detailed information about artificial neural networks can be found in the following References $[27,28]$. ANNs is a widely used numerical method which is able to model any kind of data set even complex ones.

\section{Selection of network parameters}

The artificial neurons are arranged in layers where in the input layer receive inputs $\left(u_{i}\right)$, namely experimental data and each succeeding layer receives weighted outputs $\left(\mathrm{w}_{\mathrm{ij}}, \mathrm{u}_{\mathrm{i}}\right)$ from the preceding layer asits input resulting therefore a feedforward ANN, inwhich each input is feed forward to its succeeding layer where it is treated. The outputs of the last layer constitute the outputs to the real world [29].In such a feed forward ANN a neuron in a hidden or an output layer has two tasks:

(a) It sums the weighted inputs from several connections plus a bias value and then applies a transfer function to the sum as given by (for neuron $\mathrm{j}$ of the hidden layer):

$z_{j}=f_{h}\left(\sum_{i=1}^{n} w_{j i}^{I} u_{i}+b_{h j}\right) ; j=1,2, \ldots, \mathrm{m}$

(b) It propagates the resulting value through outgoing connections to the neurons of the succeeding layer where it undergoes the same process as given by (for instance outputs $Z_{j}$ of the hidden layer fed to neuronk of the output layer gives the output $\left.V_{k}\right)$ :

$V_{k}=f_{0}\left(\sum_{j=1}^{m} w_{k j}^{h} z_{j}+b_{0 k}\right) ; k=1,2, \ldots, i$ 
Combining equations 1 and 2 the relation between the output $V_{k}$ and the inputs $u_{i}$ of the NN is obtained:

$V_{k}=f_{0}\left(\sum_{j=1}^{m} w_{k j}^{h} f_{h}\left(\sum_{i=1}^{n} w_{j i}^{I} u_{i}+b_{h j}\right)+b_{o k}\right) ; k=1,2 \ldots, i$

The output is computed by means of a transfer function, also called activation function. It is desirable that the activation function has a sort of step behavior. Furthermore, because continuity and derivability at all points are required features of the current optimization algorithms[30,31,29] three kinds of transfer function are considered in this study:

Hyperbolic tangent sigmoid transfer function:

$$
f(a)=\frac{e^{a}-e^{-a}}{e^{a}+e^{-a}}
$$

Logarithmic sigmoid transfer function:

$$
f(a)=\frac{1}{1+e^{-a}}
$$

Pure linear transfer function:

$$
f(a)=a
$$

\section{Training of network}

A Feed forwardback propagation (FFBP) which is very effective in representing nonlinear relationships among variables was used in this work BP algorithm (BPA) is the most widely used in ANN, and has different variants. FFBP with Levenberg-Marquardt (BP) training algorithm and one hidden layer was chosen because it is suitable for modeling the relationship between input data and output variable[32].

\section{Testing of network}

The criteria used for measuring the performance of the network are the absolute fraction of variation $\left(\mathrm{R}^{2}\right)$, and the root mean square error (RMSE), which can be calculated using the following equations.

The fraction of absolute variance is given by: 


$$
R^{2}=1-\frac{\sum_{i=1}^{N}\left(K_{c a l, i}-K_{e x p, i}\right)^{2}}{\sum_{i=1}^{N}\left(K_{e x p, i}\right)^{2}}
$$

The root mean square error value is calculated by

$$
R M S E=\sqrt{\sum_{i=1}^{N}\left(K_{c a l, i}-K_{e x p i}\right)^{2} / N}
$$

Here, $N$ is the number of data patterns in the independent data set, $K_{c a l, i}$ indicates the values predicted by ANN, $K_{\text {exp }, i}$ is the measured value of one data point i[33,34].

The accuracy of the model to reproduce and predict the thermal conductivity of refrigerant systems at different temperatures and pressures may be evaluated using the statistical parameters [35,36]: namely, the absolute average deviation(AAD), and the mean square error (MSE) which are defined as follows:

The mean square error value is calculated according to:

$157 \quad M S E=\frac{1}{N} \sum_{i=1}^{N}\left(K_{\text {exp }, i}-K_{c a l, i}\right)^{2}$

158 The absolute average deviation value is calculated by[29]:

$159 \quad A A D=\frac{1}{N} \sum_{i=1}^{N}\left|K_{\text {exp }, i}-K_{c a l, i}\right|$

The Average Absolute Relative Deviation:

$A A R D \%=\frac{100}{N} \sum_{i=1}^{N}\left|\frac{K_{\text {exp }, i}-K_{c a l, i}}{K_{\text {exp }, i}}\right|$

\section{Optimization of the network architecture}

Optimization of the network architecture is the major task in ANN. The parameters that affect the performance of the network are the number of neurons in the hidden layer, the number of hidden layers, the transfer function and the training algorithm. The network architecture can be optimized by varying the above parameters (using trial and error method) to achieve the results with good accuracy [33,34]. 


\section{Results and Discussion}

In the present study, a total of 3227 data points of thermal conductivity data were considered. The collected experimental data points were divided into three different sub- datasets five pure systems, (R32, R125, R134a, R152a, R143a), four binary mixtures systems(R32+R125, R32+R134a, R125+ R134a, R125+R143a), and two ternary mixtures systems (R32+R125+ R134a, R125+ R134a+ R143a) at several temperatures and pressures.Each one received 1817, 794, 616 data points respectively.

For developing the neural network model, inputs and outputs should be first defined. The input parameters included, Temperature $(T(\mathrm{k}))$ and pressure $(P(\mathrm{MPa}))$,namely two macroscopic inputs which characterize the physical conditions of the system. Molecular weight $\left(M\left(\mathrm{~g} \cdot \mathrm{mol}^{-1}\right)\right)$, critical temperature $\left(T_{c}(\mathrm{k})\right)$, critical pressure $\left(P_{c}(\mathrm{MPa})\right)$, critical density $\left(D_{c}\left(\mathrm{Kg} . \mathrm{m}^{-3}\right)\right)$, and mass fraction of liquids or vapor phase $(X)$ were the other selected inputs for pure systems they were specified as pseudo critical mixtures property for binary and ternary systems(9 inputs), and Thermal conductivity was the network output (1 output).The network is simple in structure and easily analyzed mathematically is schematically illustrated in Fig. 1 and Table1shows the physical properties values of these compounds accompanied with related references. This study employs experimental data from the open literature for each (pure, binary, ternary) systems, the details listed in Tables 2 to 4 respectively.

The available correlations for prediction can be described as follows:

$$
K=f\left(T, P, M, T_{C}, P_{C}, D_{C}, X_{i}, X_{j}, X_{k}\right)
$$

\section{Calculation of the pseudo critical mixtures properties}

The different equations of state were developed from the knowledge of the properties $P, V, T$ of pure substances. I $\mathrm{n}$ the case of mixtures of known composition, it is necessary to make use of mixing rules for calculating the average properties of the mixture. Pseudo properties in the case of critical mixtures, are generally obtained from the rule of Kays (1936): 


$$
T_{P C}=\sum_{i=0}^{n} X_{i} * T_{C i}
$$

$$
P_{P C}=\sum_{i=0}^{n} X_{i} * P_{C i}
$$

$$
\begin{gathered}
D_{P C}=\sum_{i=0}^{n} X_{i} * D_{C i} \\
M_{P C}=\sum_{i=0}^{n} X_{i} * M_{C i} \\
K=f\left(T, P, M_{P C}, T_{P C}, P_{P C}, D_{P C}, X_{i}, X_{j}, X_{k}\right)
\end{gathered}
$$

$199 \mathrm{n}=1$ for pure refrigerant, $X_{i}=1, X_{j}=0, X_{k}=0, \mathrm{n}=1,2$ for binary mixtures, $X_{i}+X_{j}=1, X_{k}=$

0 and $\mathrm{n}=1,2,3$ for ternary mixtures, $X_{i}+X_{j}+X_{k}=1$.

\section{Procedure for neural network modeling of the thermal conductivity}

ANN modeling is described consists in the following four steps: (a) extract the results from experiments or theoretical calculations (b) train the network using experimentally or theoretically predicted values(c) testing of network with data, which are not used for training,(d) identify the best network architecture based on statistical performance values $[33,34]$.

(i)phase of collection of experimental data as complete as possible. From this, the following procedure was considered:

(ii) division of data base to three parts (DB of pure systems, BD of binary systems, BD of ternary systems).

211 (iii)phase of pre-treatment and analysis of the data.

212 (iv)dividing data into three subsets-train, validation and test.

(v)phase of choice of the parameters of the neural network (neural network (FFBP), neurons number in hidden layer, activation function in hidden layer (tan-sig), activation function in output layer(Tang-sig)).

216 (vi)saving the parameters of the optimal ANN. 
Table 5 shows the structure of the optimized ANN model for each pure systems, binary systems, ternary systems and global systems Tan-sig is a sigmoid transfer function used in the hidden layer and used in the output layer for all systems, in this table, R2 values and RMSE of the trained networks have been shown for different number of hidden layer neurons. The best configuration with minimum error measure (RMSE) and appropriate $\mathrm{R}^{2}$ value. The parameters (weight and biases values) of the best selected NN model for each system (pure, binary, ternary, global) are listed in Tables 6 to 9 respectively, where $\mathrm{W}^{\mathrm{I}}$ is the input-hidden layer connection, $\mathrm{W}^{\mathrm{h}}$ is the hidden layer output connection, $\mathrm{b}_{\mathrm{hj}}$ and $\mathrm{b}_{0 \mathrm{k}}$ are biases of the neuron $\mathrm{j}$ of the hidden layer and the neuron of the output layer respectively.

Table10 shows the regression line of the network model equation during training, validation, and prediction sets of pure systems, binary systems, ternary systems and global system RMSE, MSE,AAD,AARD, and SSE, are collected in Table 11 showing that there was a significant correlation between experimental and predicted values. For each plot, the ANN method provide good results with high correlation coefficients $\left(\mathrm{R}_{\text {exp }}^{2}, \mathrm{R}_{\text {cal }}^{2}\right)$. Comparison between the output data and calculated values of the thermal conductivity of different refrigerant systems with $\left(\mathrm{R}_{\text {pure }}^{2}=0.997, \mathrm{R}_{\text {binary }}^{2}=0.998, \mathrm{R}_{\text {ternary }}^{2}=0.998, \mathrm{R}_{\text {global }}^{2}=0.997\right)$, shows lopes close to unit and an intercept values close to zero, confirming the agreement between experimental and predicted values (Fig. 2).

\section{Reduction technique}

The reduced data refers to the analysis and transformation of the input and target variables having different physical units with different range values in order to minimize the input parameters (9 inputs to 7 inputs) and to improve the learning quickness, the present study use this method to calculate the minimum and the maximum of each vector variable and scaling the data with respect the upper limits. Finally, the values of the outputs from the neural network reduced are converting before being presented. 
For data reduce, the following equations are considered:

$$
\begin{aligned}
G_{r} & =\frac{G-G_{\min }}{G_{\max }-G_{\min }} \\
X_{i} & =X_{i}+1 \\
T_{r} & =\frac{T}{T_{C}}, P_{r}=\frac{P}{P_{C}}
\end{aligned}
$$

243

245 For converting (to real value) of data estimated by ANN:

246

$$
\begin{gathered}
G=G_{r} *\left(G_{\max }-G_{\min }\right)+G_{\min } \\
K=f\left(T_{r}, P_{r}, M_{r}, D_{r}, X_{i}, X_{j}, X_{k}\right)
\end{gathered}
$$

247 Where $G$ is the original data value, $G_{r}$ is the corresponding reduced variable; min, max are the 248 minimal and the maximal values of each vector respectively.

249 The validation agreement, coefficients of determination $\left(\mathrm{R}^{2} \mathrm{exp}\right)$ and $\left(\mathrm{R}^{2} \mathrm{cal}\right)$, and different 250 errors values RMSE, MSE, AAD, AARD, and SSE, are collected in Table 12. The 251 performance of the present developed ANN (RN2, RN3) models were compared to the 252 previously developed ANN models (RN1) to estimate the thermal conductivity for original 253 (real) data and also the reduced data. The three models provided high values of the correlation 254 coefficient $\mathrm{R}^{2}$, as illustrated in Fig. 3 otherwisethe RN1model obtained was similar to RN3;

255 while the RN2 model led to a better fit of experimental data than the RN1, RN3 models.

\section{Artificial neural network prediction}

257 The assembled of new experimental data points, namely 660 data points, for harmful 258 refrigerants covered thermal conductivity range $0.0106-0.15 \mathrm{~W} / \mathrm{m}$. K, temperature range of 259 164.77-463K, and pressure range of 0.059-69.58 MPa. These collected data were distributed 260 into 363 data points for three pure systems (R22, R124, R142b), 240 data points for two 261 binary systems (R22+R142b, R22+R152a) and 57data points for one ternary system 262 (R142b+R124+R22).In this part the range of experimental data parameters and the number of 
data points accompanied with their references in Tables13, 14 and 15 for different systems (pure ,binary, ternary),respectively.

The prediction of the new data base(DB2) of the harmful refrigerants by no harmful refrigerants using (DB1) are given in Fig.4 this indicates that the new approach (RN3) improved the prediction of thermal conductivity, producing the following RMSE, MSE, AAD, AARD, SSE and $\mathrm{R}^{2}$ values, 0.0123, 0.0002, 0.0094\%, 17.92\%, 0.10 and 0.974, respectively (Table 16).

These results show the good predictive ability of the ANN model. In general, in Fig. 5 the residual did not exceed -0.025 to 0.04 for new data base (DB2) and \pm 0.02 for data base (DB1),(except for a few experimental points).The illustration of harmful refrigerants for all (pure, binary, ternary) systems by different colors that shows an appropriate ${ }^{2}$ value, 0.95,areshown in Fig. 6 this confirms that the method out performs prediction ability. Fig.7shows the prediction of DB2 by DB1 in the range $[0.01,0.03] \mathrm{W} \cdot \mathrm{m}^{-1} \cdot \mathrm{K}^{-1}$.

All experimental data points (DB1+DB2), namely the whole 3887 data points, were divided into three different sub- datasets: eight pure systems, (R32, R125, R134a, R152a, R143a, R22, R124, R142b), six binary mixtures (R32+R125, R32+R134a, R125+ R134a, R125+R143a, R22+R142b, R22+R152a), and three ternary mixtures (R32+R125+ R134a, R125+ R134a+ R143a, R142b+R124+R22), namely 2180, 1034, 673 data points respectively.

Figs. 8,9 and Table 17 shows a significant correlation with percentage residual error varying in the range of \pm 0.02 , a high $\mathrm{R}^{2}$ value, 0.998 , and fairly accurate prediction the absolute average deviation error (AARD), estimated to be 5.8\%, as well as a high robustness.

\section{Conclusion}

In this paper, a methodology for choosing an ANN model to predict thermal conductivity was presented. The methodology starts with a wide search in order to select the model with 
minimum complexity, optimal performance and choice of the respective parameters (inputs and outputs, activation functions, training algorithm, reduction technique, hidden layers). An artificial neural network model was used to predict the thermal conductivity of pure refrigerants and their binary, ternary mixtures for liquid and vapor phaseof11 systems from 3 different categories containing five pure systems (R32, R125, R134a, R152a, R143a), four binary mixtures(R32+R125, R32+R134a, R125+ R134a, R125+R143a) and two ternary mixtures (R32+R125+ R134a, R125+ R134a+ R143a).This study involved 3227 data points including the temperature, the pressure, the molecular weight, the critical temperature, the critical pressure, the critical density and the mass fraction of liquid and vapor phases of refrigerants.

In this work, the feed forward Backpropagation (BP) algorithm with LevenbergMarquardt(LM) training was applied to estimate the thermal conductivity. One relevant model (RN1) we attempted to improve their performance by using the reduction technique to attain (RN3).The best network model obtained consisted of the best fit of the validation agreement plot, and high $\mathrm{R}^{2}$ value,0.997was obtained. Furthermore, the statistical analysis showed that the model (RN3) was able to yield quite satisfactorily estimates for pure, binary and, ternary refrigerant systems, as well as the global system, the model was shown to be robust.

The performance of the proposed ANN model was also examined through its application to test a data set consisting of 660 experimental points of thermal conductivity for various systems for diverse pure, binary and ternary mixtures of refrigerants over a wide range of temperatures and pressure. The results of this evaluation indicate that the developed ANN model was capable to predict thermal conductivity with a high coefficient of determination. The results of applying the trained neural network model to the test data indicate that the method has a very good prediction capability with respect to not only the temperature and pressure ranges but also the refrigerant types. 
313 Lastly the gathering of all experimental data points DB1and DB2 (RN4)gave a high $\mathrm{R}^{2}$ value,

314 0.998, and a low average absolute relative deviation error (5.8\%).

315 Nomenclature

316 AAD Average absolute deviation

317 AARD Average absolute relative deviation

318 ANN Artificial neural network

319 CFCs Chlorofluorocarbons

320 FFBP Feed forward back propagation

321 GWP Global warming potential

322 HCFCs Hydrochlorofluorocarbons

323 HFCs Hydrofluorocarbons

$324 \mathrm{M} \quad$ Molecular mass (g.mol ${ }^{-1}$ )

$325 \quad \mathrm{M}_{\mathrm{C}} \quad$ Critical molecular mass $\left(\mathrm{g} \cdot \mathrm{mol}^{-1}\right.$ )

326 MSE Mean square error

327 N Number of data points

328 ODP Ozone depleting potential

329 P Pressure (MPa)

$330 \quad \mathrm{P}_{\mathrm{C}} \quad$ Critical pressure (MPa)

$331 \quad \mathrm{R}^{2} \quad$ Coefficient of determination

332 regression equation

333 RMSE Root mean square error

$334 \mathrm{~T} \quad$ Temperature (K)

$335 \mathrm{~T}_{\mathrm{C}} \quad$ Critical temperature $(\mathrm{K})$

336 W Weights

$337 \mathrm{X} \quad$ Mass fraction of liquid or vapor phase

$338 \alpha \quad$ Slope of the linear regression

339 equation

$340 \quad \beta \quad y$ Intercept of the linear regression

341 equation

342 Subscripts/superscripts

343 Cal Calculated

344 exp experimental

345 max maximum

346 min minimum

$347 \mathrm{n} \quad$ component

$348 *$ harmful refrigerant

349 Greek letters

$350 \quad K$ Thermal conductivity $\left(\mathrm{W} \cdot \mathrm{m}^{-1} \cdot \mathrm{K}^{-1}\right)$

$351 \quad D \quad$ Density $\left(\mathrm{Kg} \cdot \mathrm{m}^{-}{ }^{3}\right)$

$352 \quad D_{c} \quad$ Critical density $\left(\mathrm{Kg} \cdot \mathrm{m}^{-}{ }^{3}\right)$

353 Acronyms

354 ASHRAE American society of heating, refrigerating and air conditioning engineers 


\section{References}

1. World Meteorological Organization, Montreal protocol on substances that deplete the ozone layer report, WMO Bull.,1988, Vol. 37, P. 94-97.

2. J.W. Ramsdell, G.L. Colice, B.P. Ekholm, N.M. Klinger, Cumulative dose response study comparing HFA-134a albuterol sulfate and conventional CFC albuterol in patients with asthma, Ann. of Allergy Asthma Immunol., 1998, Vol. 81, P. 593-599.

3. W.T. Tsai, An overview of environmental hazards and exposure risk of hydrofluorocarbons (HFCs), Chemosphere., 2005, Vol. 61, P. 1539-1547.

4. World Meteorological Organization (WMO), 2007. Scientific Assessment of Ozone Depletion: 2006, Global Ozone, Research and Monitoring Project - Report 50, Switzerland: Geneva.

5. World Meteorological Organization (WMO), (2003), Scientific Assessment of ozone depletion: 2002, Global Ozone, Research and Monitoring Project - Report 47, Switzerland: Geneva.

6. C. H. Bridgeman, J. A. Pyle, D. E. J. Shallcross, A three-dimensional model calculation of the ozone depletion potential of 1-bromopropane (1-C3H7Br), Geophys. Res., 2000, Vol. 105 P. 493-426, 502.

7. S. C. Olsen, B. J. Hannegan, X. Zhu, , M. J. Prather, Evaluating ozone depletion from very short-lived halocarbons, Geophys. Res. Lett., 2000, Vol. 27,P. 1475-1478.

8. D. J. Wuebbles, K.O. Patten, M. T. Johnson, R., J. Kotamarthi, The new methodology for ozone depletion potentials of short-lived compounds: n-propyl bromide as an example, Geophys. Res.,2001, Vol. 106, P. 551-571.

9. P. A. Newman, J.S. Daniel, D.W. Waugh, E. R. Nash, A new formulation of equivalent effective stratospheric chlorine (EESC), Atmos. Chem. Phys., 2007, Vol. 7, P. 4537-4552.

10. P.W. Bridgman, conductivity of liquids under pressure, Proc. Am. Acad. Art Sci.,1923, Vol. 59, P. 141-169.

11. S.R.S. Sastri, K.K. Rao, A new temperature thermal conductivity relationship for predicting saturated liquid thermal conductivity, J. Chem. Eng.,1999, Vol. 74, P. 161-169.

12. B.E. Poling, J.M. Prausnitz, J.P. O'Connell, The properties of gases and liquids, fifthed. McGraw-Hill, New York., 2001.

13. F. Gharagheizi, P. Ilani-Kashkouli, M. Sattari, A..H. Mohammadi, D. Ramjugernath, D. Richon, Development of a quantitative structure liquid thermal conductivity relationship for pure chemical compounds, Fluid Phase Equilib., 2013,Vol. 355,P. 52- 80. 
14. F. Gharagheizi, P. Ilani-Kashkouli, M. Sattari, A.H. Mohammadi, D. Ramjugernath, D. Richon, Development of a general model for determination of thermal conductivity of liquid chemical compounds at atmospheric pressure, J. AIChE., 2013, Vol. 59, P. 1702-1708.

15. G. Di Nicola, E. Ciarrocchi, M. Pierantozzi, R. Stryjek, Anew equation for the thermal conductivity prediction of pure liquid compounds, J. Therm. Anal. Calorim., 2014, http://dx.doi.org/10.1007/s10973-013-3422-7.

16. J. Yata, Y. Ueda, M. Hori, Equations for the thermal conductivity of R-32, R-125, R-134a, and R-143a, Int. J. Thermophys.,2005, Vol. 26, P. 1423-1435.

17. L. Shi, X. J. Liu, X. Wang, M. S. Zhu, Prediction method for liquid thermal conductivity of refrigerant mixtures, Fluid Phase Equilib., 2000,Vol. 172, P. 293-306.

18. W.W. Focke, Correlating thermal conductivity data for ternary liquid mixtures, Int. J.Thermophys., 2008, Vol. 29, P. 1342-1360.

19. M.G. He, Z.G. Liu, J.M. Yin, New equation of state for transport properties: Calculation for the thermal conductivity and the viscosity of halogenated hydrocarbon refrigerants, Fluid Phase Equilib., 2002, Vol. 201, P. 309-320.

20. M.J. Assael, N.K. Dalaouti, K. E. Gialou, Measurements of the thermal conductivity of liquid R32, R124, R125, and R141b, Fluid Phase Equilib., 2000,Vol. 174, P. 203-211.

21. G. Scalabrin, L. Piazza, M. Grigiante, M. Baruzzo, Thermal conductivity modeling of refrigerant mixtures in a three-Parameter corresponding states format, Int. J. Thermophys., 2005, Vol. 26, P. 399-412.

22. M.L. Huber, D.G. Friend, J.F. Ely, Prediction of the thermal conductivity of refrigerants and refrigerant mixtures, Fluid Phase Equilib.,1992, Vol. 80, P. 249-261.

23. M.O. McLinden, S.A. Klein, , R.A. Perkins, An extended corresponding states model for the thermal conductivity of refrigerants and refrigerant mixtures, Int. J. Refrigeration., 2000,Vol. 23, P. 43-63.

24. S.M. Sami, J.D. Comeau, Study of viscosity and thermal conductivity effects on condensation characteristics of some new alternative refrigerant mixtures, Int. J. Energy Res., 2003, Vol. 27, P. 63-77.

25. Y. Islamoglu, A new approach for the prediction of the heat transfer rate of the wire-on-tube type heat exchanger use of an artificial neural network model, Appl. Therm. Eng.,2003, Vol. 23, P. 243-249.

26. J. Taskinen, J. Yliruusi, Prediction of physicochemical properties based on neural network modeling, Adv. Drug. Deliv. Rev.,2003, Vol. 55, P. 1163-1183.

27. L.H. Tsoukalas, R.E. Uhrig, Fuzzy and neural approaches in engineering. John Wiley et Sons Inc., 1997. 
28. S.A. Kalogirou, Applications of artificial neural networks for energy systems, Appl. Energy., 2000, Vol. 67, P. 17-35.

29. C. Si-Moussa, S. Hanini, R. Derriche, M. Bouhedda, A. Bouzidi, Prediction of high-pressure vapor liquid equilibrium of six binary systems, carbon dioxide with six esters, using an artificial neural network model, Brazilian J. Chem. Eng., 2008, Vol. 25, P. 183-199.

30. MY. Rafiq, G. Bugmann, DJ. Easterbrook, Neural network design for engineering applications, Comput. Struct.,2001, Vol. 79, P. 1541-1552.

31. Math Works . Neural network toolbox user's guide.MATLAB7.0, Release 14, MATLAB manual., 2004.

32. A. Witek-Krowiak, K. Chojnacka, D. Podstawczyk, A. Dawiec, K. Pokomeda, Application of response surface methodology and artificial neural network methods in modeling and optimization of biosorption process, Bioresour Technol., 2014, doi:10.1016/j.biortech.2014.01.021.

33. S.A. Kalogirou, Artificial intelligence for the modeling and control of combustion processes, Prog. Energy. Combust. Sci 29 (2003) 515-566.

34. A. Mellit, S.A. Kalogirou, Artificial intelligence techniques for photovoltaic applications, a review. Prog. Energy. Combust. Sci., 2008, Vol. 34, P. 574-632.

35. R. Haghbakhsh, H. Adib, P. Keshavarz, M. Koolivand, S. Keshtkari, Development of an artificial neural network model for the prediction of hydrocarbon density at high-pressure, hightemperature conditions, Termochim. Acta., 2013, Vol. 551, P. 124-130.

36. F. Amato, J. L. Gonzalez-Hernandez, J. Havel, Artificial neural networks combined with experimental design: a "soft” approach for chemical kinetics. Talanta., 2012, Vol. 93, P. 72-78.

37. Y. Tanaka, M. Nakata, T. Makita, Thermal conductivity of gaseous HFC-134a, HFC-143a, HCFC-141b, and HCFC-142b, Int. J. Thermophys.,1991, Vol. 12, P. 949-963.

38. G.K. Lavrenchenko, G.Ya. Ruvinskij, S.V. Iljushenko, V.V. Kanaev, Thermophysical properties of refrigerant R134a, Int. J. Refrigeration.,1992, Vol. 15, P. 386-392.

39. R.A. Perkins, A. Laesecke, C.A. Nieto Castrob, Polarized transient hot wire thermal conductivity measurements, Fluid Phase Equilib., 1992, Vol. 80, P. 275-286.

40. U. Gross, Y.W. Song, E. Hahne, Thermal conductivity of the new refrigerants R134a, R152a, and R123 measured by the Transient Hot-Wire method, Int. J. Thermophys., 1992, Vol. 13, P. 957-983.

41. A. Laeseck, R.A. Perkin, C.A. Nieto Castro, Thermal conductivity of R134a, Fluid Phase Equilib., 1992, Vol. 80, P. 263-274.

42. R., Yamamoto, S. Matsuo, Y. Tanaka, Thermal conductivity of halogenated ethanes, HFC134a, HCFC-123, and HCFC-141h, Int. J. Thermophys., 1993, Vol. 14, P. 79-90. 
43. M. J. Assael, E. Karagiannidis, Measurements of the thermal conductivity of R22, R123, and R134a in the temperature range 250-340 K at pressures up to $30 \mathrm{MPa}$, Int. J. Thermophys., 1993, Vol. 14. P. 183-197.

44. O. B. Tsvetkov, Yu. A. Laptev, A. G. Asambaev, Thermal conductivity of refrigerants R123, R134a, and R125 at low temperatures, Int. J. Thermophys., 1994, Vol. 15, P. 203-214.

45. U. Hammerschmidt, Thermal conductivity of a wide range of alternative refrigerants measured with an improved guarded Hot-Plate Apparatus, Int. J. Thermophys.,1995,Vol. 16, P. 1203-121.

46. S. T. Ro, J.Y. Kim, D. S. Kim, Thermal conductivity of R32 and Its mixture with R134a, Int. J. Thermophys., 1995, Vol. 16, P. 1193-1201.

47. . A. N. Gurova, U. V. Mardolcar, C. A. Nieto Castro, The thermal conductivity of Liquid 1,1,1,2-Tetrafluoroethane (HFC 134a), Int. J. Thermophys., 1997, Vol. 18, P. 1077-1087.

48. S. U. Jeong, M. S. Kim, S. T. Ro, Liquid thermal conductivity of binary mixtures of pentafluoroethane(R125) and 1,1,1,2-tetrafluoroethane (R134a), Int. J. Thermophys., 1999, Vol. 20, P. 55-62.

49. B. Le Neindre, Y. Garrabos, Measurements of the thermal conductivity of HFC-134a in the temperature range from 300 to $530 \mathrm{~K}$ and at pressures up to $50 \mathrm{MPa}$, Int. J. Thermophys.,1999, Vol. 20, P. 1379-1401.

50. A.V. Baginsky, A.S. Shipitsyna, Thermal conductivity and thermal diffusivity of the R134arefrigerant in the liquid state, Thermophys. Aeromech. 16 (2009) 267-273.

51. Y. Tanaka, S. Matsuo, S. Taya, Gaseous thermal conductivity of difluoromethane (HFC-32), pentafluoroethane (HFC-125), and their mixtures, Int. J. Thermophys., 1995, Vol. 16, P. 121131.

52. M. J. Assael, L. Karagiannidis, Measurements of the thermal conductivity of liquid R32, R124, R125, and R141b, Int. J. Thermophys.,1995, Vol. 16, P. 851-865.

53. O. B. Tsvetkov, A. V. Kletski, Yu. A. Laptev, A. J. Asambaev, I. A. Zausaev, Thermal conductivity and PVT measurements of Pentafluoroethane (refrigerant HFC-125), Int. J. Thermophys., 1995, Vol. 16, P. 1185-1192.

54. U. Gross, Y. W. Song ,Thermal conductivities of new refrigerants R125 and R32 Measured by the Transient Hot-Wire method, Int. J. Thermophys., 1996, Vol. 17, P. 607-619.

55. S. T. Ro, M. S. Kim, S. U. Jeong, ). Liquid thermal conductivity of binary mixtures of difluoromethane (R32) and pentafluoroethane (R125), Int. J. Thermophys., 1997, Vol. 18, P. 991-999.

56. S. H. Kim, D. S. Kim, M. S. Kim, S.T. Ro, The thermal conductivity of R22, R142b, R152a, and their mixtures in the liquid State, Int. J. Thermophys., 1993, Vol. 14, P. 937-950.

57. O. B. Tsvetkov, Yu. A. Laptev, A.G. Asambaev, The thermal conductivity of binary mixtures of liquid R22 with R142b and R152a at low temperatures, Int. J. Thermophys., 1996, Vol. 17, P. 597-606. 
58. A.N. Gurova, U.V. Mardolcar, C.A. Nieto Castro, Thermal conductivity of 1,1-difluoroethane (HFC-152a), Int. J. Thermophys., 1999, Vol. 20, P. 63-72.

59. S.H. Lee, M.S. Kim, S.T. Ro, Thermal conductivity of 1,1,1-trifluoroethane (R143a) and R404A in the liquid phase, J. Chem. Eng., 2001, Vol. 46, P. 1013-1015.

60. X. Gao, Y. Nagasaka, A. Nagashima, Thermal conductivity of binary refrigerant mixtures of HFC-32/125 and HFC-32/134a in the liquid phase, Int. J. Thermophys., 1999, Vol. 20, P. 14031415.

61. V. Z. Geller, B.V. Nemzer, U.V. Cheremnykh, Thermal conductivity of the refrigerant mixtures R404A, R407C, R410A, and R507A, Int. J. Thermophys., 2001, Vol. 22, P. 1035-1043.

62. A.V. Baginsky, A.S. Shipitsiyna, Thermal conductivity of liquid R507 refrigerant, Thermophys. Aeromech.,2008, Vol. 15, P. 291-295.

63. O.I. Verba, Thermal conductivity of refrigerant 507A in gaseous state*, Thermophys. Aeromech., 2011, Vol. 18, P. 151-154.

64. [66] X. Gao, Y. Nagasaka, A. Nagashima, Thermal conductivity of ternary refrigerant mixtures of HFC-32/125/134a in the liquid phase, Int. J. Thermophys., 1999, Vol. 20, P. 1417-1424.

65. S. U. Jeong, M.S. Kim, S.T. Ro, ). Liquid thermal conductivity of ternary mixtures of difluoromethane(R32), pentafluoroethane (R125), and 1,1,1,2-tetrafluoroethane (R134a), Int. J. Thermophys., 2000, Vol. 21, P. 319-328.

66. O. I. Verba, E. P. Raschektaeva, S.V. Stankus, Experimental study of thermal conductivity of the R407C refrigerant in the vapor phase, High Temp., 2012, Vol. 50, P. 200-203.

67. O. I. Verba, Thermal conductivity of gaseous refrigerant R 404A*, Thermophys. Aeromech., 2007, Vol. 14, P. 165-168.

68. A.V. Baginsky, A. S. Shipitsiyna, Thermal conductivity of liquid refrigerant R404A*, Thermophys. Aeromech., 2007,Vol. 14, P. 165-168.

69. T. Makita, Y.Tanaka, Y. Morimoto, M. Noguchi, H. Kubota, Thermal conductivity of gaseous Fluorocarbon refrigerants R 12, R 13, R 22, and R 23, under pressure, Int. J. Thermophys., 1981, Vol. 2, P. 249-268.

70. O. I. Verba, , E. P. Raschektaeva, S.V. Stankus, Thermal conductivity of refrigerant R-415A in the vapor phase, Thermophys. Aeromech., 2013, Vol, 20, P. 477-479.

71. O. I. Verba, E. P. Raschektaeva, S. V.Stankus, Experimental study of thermal conductivity of refrigerant R-409A in vapor phase*, Thermophys. Aeromech.,2011, Vol. 18, P. 661-664. 
Table 1

The critical properties of compounds used in this work

\begin{tabular}{|c|c|c|c|c|c|}
\hline Component & Molecular weight (g/mol) & $\boldsymbol{T}_{\mathbf{C}}(\mathbf{K})$ & $\mathbf{P}_{\mathbf{C}}(\mathbf{M p a})$ & $\mathbf{D}_{\mathbf{C}}\left(\mathbf{K g} / \mathbf{m}^{3}\right)$ & Reference \\
\hline R32 & 50.020 & 351.55 & 5.83000 & 430.0 & {$[56]$} \\
R125 & 120.02 & 339.45 & 3.59000 & 571.0 & {$[56]$} \\
R134a & 102.00 & 374.18 & 4.05629 & 508.0 & {$[49]$} \\
R152a & 66.050 & 386.44 & 4.52000 & 365.0 & {$[44]$} \\
R143a & 84.040 & 346.25 & 3.81100 & 434.0 & {$[44]$} \\
R22* & 86.470 & 369.35 & 4.99000 & 513.0 & {$[56]$} \\
R124* & 136.48 & 395.65 & 3.63400 & 560.0 & {$[44]$} \\
R142b* & 100.50 & 410.25 & 4.24600 & 459.0 & {$[44]$} \\
R152a* & 66.050 & 386.44 & 4.52000 & 365.0 & {$[44]$} \\
\hline
\end{tabular}


Table 2

Sources and ranges of data base used in this work for pure systems

\begin{tabular}{|c|c|c|c|c|c|c|}
\hline Component & $\mathrm{T}(\mathrm{K})$ & $\overline{\mathbf{P}(\text { Mpa) }}$ & $\overline{\mathbf{X}_{\mathbf{i}}}$ & $\left.\mathbf{W} \cdot \mathbf{m}^{-1} \mathbf{K}^{-1}\right)$ & & Reference \\
\hline \multirow{14}{*}{ R134a } & 293.15-353.15 & $0.10-2.540$ & 1 & $0.0123-0.0256$ & 32 & [37] \\
\hline & $272.46-400.47$ & 0.1005-8.943r & 1 & $0.1165-0.0948$ & 34 & [38] \\
\hline & 202.83-303.05 & 1.2919-5.177، & 1 & $0.08445-0.1272$ & 28 & [39] \\
\hline & 253.25-363.15 & $0.096-6.097$ & 1 & $0.01205-0.10605$ & 76 & {$[40]$} \\
\hline & 203.00-393.00 & $0.09-68.201$ & 1 & $0.01036-0.14495$ & 207 & {$[41]$} \\
\hline & 273.15-363.15 & $0.10-2.8$ & 1 & 0.01096-0.02036 & 38 & [42] \\
\hline & 252.97-333.20 & $1.71-22.43$ & 1 & $0.0707-0.1113$ & 32 & [43] \\
\hline & 169.87-290.06 & 10.00 & 1 & $0.0862-0.1430$ & 19 & [44] \\
\hline & $303.00-463.00$ & 0.10 & 1 & $0.01376-0.02758$ & 05 & [45] \\
\hline & 223.15-323.15 & $2-25$ & 1 & $0.07448-0.12087$ & 24 & [46] \\
\hline & 213.01-292.88 & $1.00-21.34$ & 1 & 0.087297-0.13048 & 51 & [47] \\
\hline & $232.75-323.25$ & $2.00-20.00$ & 1 & $0.0751-0.1184$ & 23 & [48] \\
\hline & 295.85-532.94 & $0.1 .0-50.00$ & 1 & $0.01276-0.10494$ & 521 & [49] \\
\hline & 295.85-354.95 & $1.379-4.147$ & 1 & $0.05715-0.08401$ & 102 & [50] \\
\hline \multirow{7}{*}{ R125 } & 172.74-290.02 & 10.00 & 1 & $0.0679-0.1116$ & 16 & [44] \\
\hline & 283.15-333.15 & $0.100-2.010$ & 1 & $0.01229-0.01777$ & 51 & [51] \\
\hline & 253.04-313.46 & $1.24-16.03$ & 1 & $0.0578-0.0793$ & 19 & [52] \\
\hline & 187.43-413.61 & $0.18-6.040$ & 1 & $0.011-0.1075$ & 28 & [53] \\
\hline & 254.45-354.35 & 0.104-7.033 & 1 & $0.01212-0.08426$ & 93 & {$[54]$} \\
\hline & 231.25-324.05 & $2.00-20.00$ & 1 & $0.0524-0.0984$ & 24 & [55] \\
\hline & 231.25-324.05 & $2.00-20.00$ & 1 & $0.0524-0.0984$ & 24 & [48] \\
\hline \multirow{5}{*}{ R32 } & 283.15-333.15 & $0.10-3.00$ & 1 & $0.01084-0.02025$ & 51 & {$[51]$} \\
\hline & 252.67-312.83 & $3.68-17.63$ & 1 & $0.1148-0.1704$ & 21 & [52] \\
\hline & 223.15-323.15 & $2.00-20.00$ & 1 & $0.11035-0.1984$ & 22 & [46] \\
\hline & 233.45-334.95 & $0.098-6.194$ & 1 & $0.01081-0.17762$ & 55 & [54] \\
\hline & 232.55-322.95 & $2.00-20.00$ & 1 & 0.1141-0.1927 & 22 & [55] \\
\hline \multirow{5}{*}{ R152a } & $263.15-363.15$ & $0.082-6.22$ & 1 & $0.01215-0.1263$ & 67 & [40] \\
\hline & 223.15-323.15 & $2.1-20.1$ & 1 & $0.0928-0.145$ & 25 & [56] \\
\hline & $303-423$ & 0.1 & 1 & $0.01491-0.02592$ & 4 & [45] \\
\hline & 189.61-299.33 & 7.71-8.55 & 1 & $0.1076-0.159$ & 11 & [57] \\
\hline & 211.69-294.29 & $0.79-18.5$ & 1 & $0.10259-0.14752$ & 38 & [58] \\
\hline \multirow{3}{*}{ R143a } & 293.15-353.15 & $0.1-3.98$ & 1 & $0.0126-0.0375$ & 29 & [37] \\
\hline & $298-383$ & 0.1 & 1 & $0.0123-0.01873$ & 4 & [45] \\
\hline & 233.15-323.45 & $2-20$ & 1 & 0.0576-0.1121 & 21 & [59] \\
\hline
\end{tabular}


Table 3

Sources and ranges of data base used in this work for binary systems

\begin{tabular}{|c|c|c|c|c|c|c|}
\hline $\begin{array}{c}\text { Binary } \\
\text { Systems }\end{array}$ & $\mathrm{T}(\mathrm{K})$ & P(Мpa) & $X_{i}+X_{J}=1$ & $\mathbf{K}\left(\mathbf{W} \cdot \mathbf{m}^{-1} \mathbf{K}^{-1}\right)$ & $\mathbf{N}$ & Reference \\
\hline $\begin{array}{c}\text { R32+R125 } \\
\text { R410A }\end{array}$ & $\begin{array}{l}283.15-298.15 \\
232.65-323.95 \\
213-293 \\
255.04-409.8\end{array}$ & $\begin{array}{l}0.10-1.20 \\
2-20 \\
2-30 \\
0.101-3.69\end{array}$ & $\begin{array}{l}1876-0.8222 \\
0.2522-0.7595 \\
0.249-0.75 \\
0.5+0.5=1\end{array}$ & $\begin{array}{l}0.0117-0.01502 \\
0.0639-0.1667 \\
0.0814-0.1785 \\
0.02276-0.00998\end{array}$ & $\begin{array}{l}69 \\
120 \\
60 \\
50\end{array}$ & $\begin{array}{l}{[51]} \\
{[55]} \\
{[60]} \\
{[61]}\end{array}$ \\
\hline R32+R134a & $\begin{array}{l}223.15-323.15 \\
193.2-316.1\end{array}$ & $\begin{array}{l}2-25 \\
2-30\end{array}$ & $\begin{array}{l}0.3057-0.7496 \\
0.249-0.75\end{array}$ & $\begin{array}{l}0.08165-0.17378 \\
0.0846-0.1953\end{array}$ & $\begin{array}{l}72 \\
84\end{array}$ & $\begin{array}{l}{[46]} \\
{[60]}\end{array}$ \\
\hline R125+R134a & $232.75-323.55$ & $2-20$ & $0.191-0.785$ & $0.0597-0.1143$ & 98 & [48] \\
\hline R507A & $\begin{array}{l}254.71-372.17 \\
297.95-332.55 \\
312.59-424.24\end{array}$ & $\begin{array}{l}0.101-2.647 \\
1.465-3.775 \\
0.105-1.902\end{array}$ & $0.5+0.5=1$ & $\begin{array}{l}0.01007-0.02138 \\
0.05-0.0637 \\
0.01468-0.02528\end{array}$ & $\begin{array}{l}34 \\
128 \\
79\end{array}$ & $\begin{array}{l}{[61]} \\
{[62]} \\
{[63]}\end{array}$ \\
\hline
\end{tabular}

\section{Table 4}

Sources and ranges of data base used in this work for ternary systems

\begin{tabular}{|l|l|l|l|l|l|l|}
\hline $\begin{array}{l}\text { Ternary } \\
\text { systems }\end{array}$ & \multicolumn{1}{|c|}{$\mathbf{T}$ (K) } & $\mathbf{P}$ (Mpa) & $+\mathbf{X}_{\mathbf{J}}+\mathbf{X}_{\mathbf{k}}=\mathbf{1}$ & $\mathbf{K}\left(\mathbf{W} \cdot \mathbf{~ m}^{-1} \mathbf{K}^{\mathbf{1}} \mathbf{)}\right.$ & $\mathbf{N}$ & Reference \\
\hline $\begin{array}{l}\text { R32+R125 } \\
\text { +R134a }\end{array}$ & $193.1-293$ & $2-30$ & & & & \\
407C & $253.27-389.83$ & $0.101-2.447$ & $0.23+0.25+0.52=1$ & $0.00968-0.02012$ & 38 & {$[61]$} \\
407C & $303.9-424.25$ & $0.1055-2.038$ & $0.23+0.25+0.52=1$ & $0.0133-0.02454$ & 97 & {$[66]$} \\
\hline & $252.8-393.09$ & $0.101-2.763$ & $0.44+0.04+0.52=1$ & $0.0099-0.02234$ & 46 & {$[61]$} \\
404A & $233.55-322.95$ & $2-20$ & $0.44+0.04+0.52=1$ & $0.0563-0.1056$ & 24 & {$[59]$} \\
& $311.32-428.94$ & $0.13-1.841$ & $0.44+0.04+0.52=1$ & $0.02584-0.01451$ & 91 & {$[67]$} \\
& $297.85-332.65$ & $1.277-3.818$ & $.44+0.04+0.52=1$ & $0.05073-0.06532$ & 108 & {$[70]$} \\
\hline
\end{tabular}

N: Number of experimental data; R410A (R32, R125: 50\%, 50\%); R507A (R125, R143a: 50\%, 50\%),407C (R32, R125, R134a: 23\%, 25\%, 52\%); 404A (R125, R134, R143: 44\%, 4\%, 52\%).

Table 5

The values of coefficient of determination, $\mathbf{R}^{2}$ and $\mathrm{RMSE}$ of different transfer function with the optimal number of neurons in each case

\begin{tabular}{|c|c|c|c|c|c|c|}
\hline \multirow{2}{*}{ 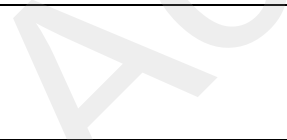 } & \multirow{2}{*}{$\begin{array}{l}\text { Type of } \\
\text { Network }\end{array}$} & Input layer & Hidden layer & Output layer & & \\
\hline & & $\begin{array}{l}\text { Neurons } \\
\text { Number }\end{array}$ & $\begin{array}{l}\text { Activation } \\
\text { function }\end{array}$ & $\begin{array}{c}\text { Activation } \\
\text { function }\end{array}$ & $\overline{\mathbf{R}^{2}}$ & RMSE \\
\hline \multirow{5}{*}{ Pure systems } & FFBP & 13 & Logsig & Tansig & 0.99312 & 0.0039 \\
\hline & FFBP & 16 & Logsig & Purelin & 0.99411 & 0.0033 \\
\hline & FFBP & 13 & Tansig & Tansig & 0.99615 & 0.0027 \\
\hline & FFBP & 19 & Tansig & Purelin & 0.98434 & 0.0054 \\
\hline & FFBP & 25 & Purelin & Tansig & 0.75703 & 0.0200 \\
\hline
\end{tabular}




\begin{tabular}{|l|l|l|l|l|l|l|}
\hline & FFBP & 16 & Logsig & Tansig & 0.9971 & 0.0037 \\
Binary systems & FFBP & 15 & Logsig & Purelin & 0.9956 & 0.0045 \\
& FFBP & $\mathbf{1 3}$ & Tansig & Tansig & $\mathbf{0 . 9 9 8 0}$ & $\mathbf{0 . 0 0 3 0}$ \\
& FFBP & 19 & Tansig & Purelin & 0.9911 & 0.0064 \\
& FFBP & 25 & Purelin & Tansig & 0.9909 & 0.0065 \\
\hline \multirow{3}{*}{ Ternary systems } & FFBP & 15 & Logsig & Tansig & 0.9934 & 0.0046 \\
& FFBP & 16 & Logsig & Purelin & 0.9928 & 0.0048 \\
& FFBP & $\mathbf{1 2}$ & Tansig & Tansig & $\mathbf{0 . 9 9 8 3}$ & $\mathbf{0 . 0 0 2 3}$ \\
& FFBP & 19 & Tansig & Purelin & 0.9933 & 0.0046 \\
& FFBP & 25 & Purelin & Tansig & 0.9080 & 0.0157 \\
\hline \multirow{3}{*}{ Global system(RN1) } & FFBP & 09 & Tansig & Tansig & 0.9925 & 0.0063 \\
& FFBP & 16 & Logsig & Tansig & 0.9941 & 0.0057 \\
& FFBP & 15 & Logsig & Purelin & 0.9825 & 0.0081 \\
& FFBP & $\mathbf{1 3}$ & Tansig & Tansig & $\mathbf{0 . 9 9 6 6 7}$ & $\mathbf{0 . 0 0 3 6}$ \\
& FFBP & 19 & Tansig & Purelin & 0.99279 & 0.0052 \\
& FFBP & 25 & Purelin & Tansig & 0.81528 & 0.0251 \\
\hline
\end{tabular}

Table 6

Weights and biases of the optimal ANN architecture (Pure systems)

\begin{tabular}{|c|c|c|c|c|c|c|c|c|}
\hline \multicolumn{7}{|c|}{ Input-Hiddenlayer } & \multicolumn{2}{|c|}{ Output layer } \\
\hline & \multicolumn{5}{|c|}{ Weights $\left(\mathbf{w}_{\mathbf{j}}^{\mathbf{I}}\right)$} & Bias & Weights $\left(\mathbf{w}_{\mathbf{j}}^{\mathbf{h}}\right)$ & Bias \\
\hline $\mathbf{T}$ & $\mathbf{P}$ & PC & $\mathbf{T}_{\mathbf{P C}}$ & $\mathbf{P}_{\mathrm{PC}}$ & $\mathbf{D}_{\mathbf{P C}}$ & $\mathbf{b}_{\mathbf{h j}}$ & $\lambda$ & $\mathbf{b}_{\mathrm{OK}}$ \\
\hline 4.1835 & -26.0332 & 3.548 & -0.73562 & 1.9594 & -2.3406 & -24.0384 & 8.1261 & -1.078 \\
\hline 3.1419 & 3.6054 & -0.36381 & -1.9651 & -2.152 & -4.9293 & 5.0308 & -2.9587 & \\
\hline 1.0815 & -1.6325 & 0.4712 & -0.27291 & -0.90651 & -1.3208 & -2.0767 & -0.78916 & \\
\hline-1.0815 & 0.8861 & 1.4178 & 1.1202 & -1.3863 & 0.31068 & 0.21321 & -1.852 & \\
\hline 4.186 & -27.8174 & 3.0948 & -0.53317 & 1.8773 & 0.31068 & -25.6167 & -12.7112 & \\
\hline 0.018849 & -10.7969 & -2.5628 & -4.3041 & 4.3532 & -5.1926 & -3.7738 & 3.0238 & \\
\hline-2.758 & -3.7144 & -0.13042 & -0.16113 & -3.4486 & -3.4213 & -3.7011 & -1.4468 & \\
\hline 3.643 & 3.5253 & 1.06 & 1.6562 & -1.7157 & 3.1487 & -0.10328 & 1.4675 & \\
\hline 0.20958 & 21.8944 & 7.2547 & 7.4236 & -5.9335 & 7.6625 & 9.693 & 9.5999 & \\
\hline 0.67147 & -0.19387 & 1.7556 & 0.184331 & 0.37153 & -0.39813 & 0.68139 & -2.7786 & \\
\hline-3.7149 & 1.3188 & -2.8947 & -1.3753 & -4.3276 & -6.2882 & -4.335 & 3.7792 & \\
\hline-4.7261 & 33.3708 & 9.3397 & 11.3213 & 10.045 & 11.4176 & 10.549 & -4.4501 & \\
\hline 1.7355 & -0.72955 & -0.66524 & -0.53499 & -1.8261 & -1.2245 & 2.8832 & 1.4051 & \\
\hline
\end{tabular}

Table 7

Weights and biases of the optimal ANN architecture (Binary systems)

Input-Hidden layer connections
\begin{tabular}{|c|c|c|c|c|c|c|c|c|}
\hline \multicolumn{7}{|c|}{ Weights $\left(\mathbf{w}_{\mathbf{j}}^{\mathbf{I}}\right)$} \\
\hline $\mathbf{T}$ & $\mathbf{P}$ & $\mathbf{M}_{\mathbf{P C}}$ & $\mathbf{T}_{\mathbf{P C}}$ & $\mathbf{P}_{\mathbf{P C}}$ & $\mathbf{D}_{\mathbf{P C}}$ & $\mathbf{X}_{\mathbf{I}}$ & $\mathbf{X}_{\mathbf{I}}$ & $\mathbf{b}_{\mathbf{h j}}$ \\
\hline
\end{tabular}




\begin{tabular}{|c|c|c|c|c|c|c|c|c|c|c|c|c|}
\hline-1.1368 & \multicolumn{2}{|c|}{0.35087} & \multicolumn{2}{|c|}{0.061351} & \multicolumn{2}{|c|}{-0.092349} & \multicolumn{2}{|c|}{0.19155} & 0.015487 & 0.9552 & 0.93462 & 1.9505 \\
\hline-0.52848 & \multicolumn{2}{|c|}{-0.27209} & \multicolumn{2}{|c|}{-0.34413} & \multicolumn{2}{|c|}{1.5926} & \multicolumn{2}{|c|}{-1.8845} & -2.2342 & -0.89647 & 0.091077 & 0.72922 \\
\hline-9.2944 & \multicolumn{2}{|c|}{15.2025} & \multicolumn{2}{|c|}{-1.3931} & \multicolumn{2}{|c|}{-5.7894} & \multicolumn{2}{|c|}{-0.69764} & -3.0922 & -1.2185 & 0.63763 & 10.2253 \\
\hline 0.74509 & \multicolumn{2}{|c|}{-0.046277} & \multicolumn{2}{|c|}{-2.1833} & \multicolumn{2}{|c|}{1.0658} & \multicolumn{2}{|c|}{1.6071} & -1.7698 & 2.1854 & -0.63659 & -2.6666 \\
\hline-5.463 & \multicolumn{2}{|c|}{1.3739} & \multicolumn{2}{|c|}{0.35375} & \multicolumn{2}{|c|}{-3.044} & \multicolumn{2}{|c|}{-0.13265} & 3.0506 & -0.70419 & 1.0513 & 0.063846 \\
\hline 9.2908 & \multicolumn{2}{|c|}{-15.1812} & \multicolumn{2}{|c|}{0.67375} & \multicolumn{2}{|c|}{5.4099} & \multicolumn{2}{|c|}{0.5982} & 3.5809 & 0.51316 & -0.9871 & -9.9995 \\
\hline 0.5417 & -0.0 & 49875 & & 994 & & 517 & & 231 & -1.1869 & 2.38 & -1.1708 & -2.6427 \\
\hline-0.52533 & -0.2 & 8921 & & 2 & & 6 & & 79 & 81 & -0.47692 & 0.60561 & 0.72659 \\
\hline-5.2406 & & 3486 & & 74 & & 27 & & 27 & 57 & -1.1621 & 0.60392 & -0.0015349 \\
\hline-0.22325 & -0.5 & 5471 & & 7886 & & 55 & & 2742 & 0.096161 & 1.0705 & 1.0084 & -2.6841 \\
\hline-0.69205 & 0.0 & 2437 & & 158 & & & & 94 & 1.371 & -0.51057 & -0.9332 & -1.8227 \\
\hline 3.4761 & 21. & 2807 & & 33 & & & -0.0 & 736 & -0.4 & 0.7 & 307 & 21.9264 \\
\hline 3.4725 & & 7136 & & 232 & & 258 & & 431 & -0.20199 & 0.64987 & 0.51264 & 14.4721 \\
\hline & & & & & & & & 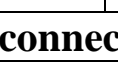 & IS & & & 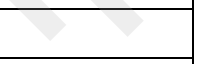 \\
\hline Neuro & & 1 & & 2 & & 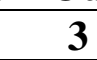 & & 4 & 5 & 6 & 7 & 8 \\
\hline Weights & & 2.198 & & 2.554 & & -3.68 & & 1.0359 & 0.43907 & -3.6939 & -1.1012 & -2.4532 \\
\hline Neuron & & 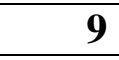 & & 10 & & & & 12 & 13 & ias ( & & \\
\hline $\operatorname{ghts}\left(\mathbf{w}_{\mathbf{j}}^{\mathbf{h}}\right)$ & & -0.445 & & -0.527 & & 3.80 & & 8.5022 & -8.5843 & & 292 & \\
\hline
\end{tabular}

Table 8

Weights and biases of the optimal ANN architecture (Ternary systems)

\section{Input-Hidden layer connections}

\begin{tabular}{|c|c|c|c|c|c|c|c|c|c|c|}
\hline \multicolumn{10}{|c|}{ Weights $\left(w_{j}^{I}\right)$} & \multirow{2}{*}{\begin{tabular}{|l|} 
Bias \\
$\mathbf{b}_{\mathbf{h j}}$ \\
\end{tabular}} \\
\hline $\mathbf{T}$ & $\mathbf{P}$ & $\mathbf{M}_{\mathbf{P C}}$ & $\mathbf{T}_{\mathbf{P C}}$ & $\mathbf{P}_{\mathbf{P C}}$ & $\mathbf{D}_{\mathbf{P C}}$ & $X_{I}$ & \multicolumn{2}{|c|}{$\mathbf{X}_{\mathrm{J}}$} & $\mathbf{X}_{\mathrm{K}}$ & \\
\hline-6.7739 & 31.4165 & 3.2577 & 0.39732 & 1.036 & -2.527 & -3.2365 & \multicolumn{2}{|c|}{-4.0231} & -2.7244 & 25.5898 \\
\hline-0.29425 & -0.9485 & $5 \mid-0.21473$ & 0.21213 & 1.2451 & -0.7214 & 0.11886 & \multicolumn{2}{|c|}{-0.74649} & -2.0618 & 3.0249 \\
\hline-2.47 & 0.18387 & 0.75536 & 1.8232 & 0.99324 & -0.27279 & 0.11747 & \multicolumn{2}{|c|}{1.3872} & -0.52704 & -1.2649 \\
\hline 6.7677 & -0.902 & 0.55508 & -0.22995 & -0.18338 & 1.1255 & -0.24203 & \multicolumn{2}{|c|}{-0.49338} & 0.82683 & -1.0511 \\
\hline 12.3596 & -35.956 & -3.9554 & -1.2256 & -0.82614 & 2.2185 & 3.2681 & \multicolumn{2}{|c|}{5.1516} & 3.3689 & -28.9329 \\
\hline-8.6059 & 30.2842 & 3.1171 & 0.62656 & 0.4441 & -3.11 & -3.9329 & \multicolumn{2}{|c|}{-4.3703} & -3.1823 & 24.2517 \\
\hline 5.3871 & -0.45338 & \begin{tabular}{l|l}
88 & 0.17102
\end{tabular} & 0.88106 & 1.5367 & 0.51125 & -0.22673 & \multicolumn{2}{|c|}{0.45733} & -0.37837 & 0.89032 \\
\hline-4.024 & 0.6629 & $9 \quad-0.072903$ & 0.8168 & 1.61 & 0.075941 & -0.90256 & \multicolumn{2}{|c|}{0.61739} & -0.52554 & 0.30976 \\
\hline-0.55489 & 0.97025 & 0.81368 & -1.2384 & -1.1274 & 0.27533 & -0.68395 & \multicolumn{2}{|c|}{2.6689} & -0.7989 & -0.52271 \\
\hline-1.9379 & 0.18981 & $1 \mid-0.039593$ & -0.46625 & -1.1118 & -0.55954 & 1.1551 & \multicolumn{2}{|c|}{0.28289} & 0.45203 & -1.8192 \\
\hline-0.93241 & 0.119 & -1.3877 & -0.25618 & -0.12932 & 0.32091 & 0.38547 & & 1658 & -0.77965 & -2.7939 \\
\hline-1.7399 & 0.0875 & 0.91754 & 0.57086 & -0.14689 & 0.19638 & 0.45431 & -0.5 & 1917 & -0.50043 & -0.42572 \\
\hline Hidden & 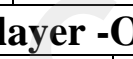 & 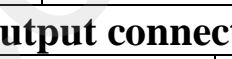 & & & & & & & & \\
\hline \begin{tabular}{|l|} 
Neuron \\
\end{tabular} & & 1 & 2 & 3 & 4 & 5 & & & 6 & 7 \\
\hline Weights( & $\left.w_{\mathbf{j}}^{\mathbf{h}}\right)$ & 5.5039 & 0.16279 & 2.6773 & 0.11532 & -5.108 & & -9.9 & 32 & 0.33928 \\
\hline Neuron & & 8 & 9 & 10 & 11 & 12 & & & Bias (b $\mathbf{b}_{0}$ & \\
\hline \begin{tabular}{|l|} 
Weights \\
\end{tabular} & $\left(\mathbf{w}_{\mathbf{j}}^{\mathbf{h}}\right)$ & 0.45079 & 0.36474 & 3.0944 & -1.4005 & -2.67 & & & 1.1341 & \\
\hline
\end{tabular}


Table 9

Parameters (weight and bias) of the ANN of global systems (pure systems + Binary systems + Ternary systems)

\begin{tabular}{|c|c|c|c|c|c|c|c|c|c|c|c|}
\hline & \multicolumn{11}{|c|}{ Input-Hidden layer connections } \\
\hline & \multicolumn{10}{|c|}{ Weights $\left(w_{j}^{I}\right)$} & \multirow[t]{2}{*}{ Bias } \\
\hline $\mathbf{T}$ & \multicolumn{2}{|l|}{$\mathbf{P}$} & $\mathrm{PC}$ & c & C & c & \multirow[b]{2}{*}{3.3188} & & & $\mathbf{X}_{\mathbf{K}}$ & \\
\hline 6.957 & \multicolumn{2}{|c|}{-12.2166} & 2.9853 & -1.3155 & 2.0151 & -2.1339 & & \multicolumn{2}{|c|}{2.9528} & 2.015 & -9.5758 \\
\hline 1.4863 & \multicolumn{2}{|c|}{0.65639} & -3.5468 & -3.212 & -0.67515 & -5.9821 & 5.0425 & \multicolumn{2}{|c|}{-6.9349} & 3.4699 & -3.1199 \\
\hline 10.335 & \multicolumn{2}{|c|}{-81.7504} & 6.0135 & -1.6097 & 4.2269 & -3.718 & 17.1393 & \multicolumn{2}{|c|}{16.9112} & 12.3423 & -63.1976 \\
\hline 11.5506 & \multicolumn{2}{|c|}{-19.1889} & 1.0367 & -2.2234 & -4.1378 & -10.7707 & 0.96966 & \multicolumn{2}{|c|}{6.8634} & 4.6281 & -15.8314 \\
\hline-5.1279 & \multicolumn{2}{|c|}{1.2623} & 7.8443 & 5.3259 & -5.9467 & 5.445 & -8.7607 & 11.7 & 747 & -4.9305 & -1.0918 \\
\hline 1.4196 & 0.70 & 906 & -5.2684 & -3.4587 & -1.2712 & -5.6834 & 6.5972 & -7.3 & 54 & 4.5641 & -3.5073 \\
\hline-10.6208 & 23.0 & 268 & -10.2401 & 2.4067 & -6.6956 & 6.7064 & -4.5555 & -4.6 & & -3.5096 & 14.769 \\
\hline 1.1016 & -1.1 & & -9.782 & 0.29611 & -5.9066 & 6.0638 & 0.4596 & 0.41 & 237 & 0.30055 & -1.9767 \\
\hline 10.1973 & -21.9 & 597 & 9.7397 & -2.2774 & 6.3447 & -6.3376 & 4.2893 & 4.3 & & 3.3243 & -14.2148 \\
\hline-0.81496 & 0.04 & 279 & -1.263 & 0.050917 & -0.43153 & 0.67735 & -0.233 & -0.2 & 751 & -0.17218 & \begin{tabular}{|l}
-2.5694 \\
\end{tabular} \\
\hline-5.9358 & 41.3 & 513 & -5.2625 & 1.0139 & -2.699 & 3.4824 & -8.3715 & -8.3 & & -6.1807 & 31.8419 \\
\hline-5.8418 & 41.3 & 729 & -4.9489 & 0.9846 & -2.5971 & 3.2643 & -7.8934 & -7.8 & & -5.8206 & 32.3549 \\
\hline-7.2882 & 13.02 & 75 & -2.485 & 3.8655 & -2.1155 & 8.6409 & 0.18179 & -2.7 & & -1.5401 & 10.0868 \\
\hline & & & & Hidden & yer -Ou & t connec & ions & & & & \\
\hline Neuror & & 1 & & 2 & 3 & 4 & 5 & & & 6 & 7 \\
\hline Weights( & $\left.w_{\mathbf{j}}^{\mathbf{h}}\right)$ & 0.5 & 244 & -1.9121 & -2.2127 & 0.4186 & -0.034 & 145 & & 3947 & -5.637 \\
\hline Neuron & & & 8 & 9 & 10 & 11 & 12 & & & 13 & Bias $\left(\mathbf{b}_{\mathrm{OK}}\right)$ \\
\hline Weights & $\left(\mathbf{w}_{\mathbf{j}}^{\mathbf{h}}\right)$ & 0.2 & 1922 & -6.1822 & 11.9478 & 7.0574 & -9.03 & & & 9239 & 11.0953 \\
\hline
\end{tabular}

\section{Table 10}

Linear regression vectors (linear equation: $\gamma^{c a l}=\alpha \gamma^{e x p}+\beta$, with, $\alpha=$ slope $\beta=y$ intercept, $R^{2}$ correlation coefficient)

\begin{tabular}{|c|c|c|c|c|c|}
\hline Systems & $\mathbf{N}$ & 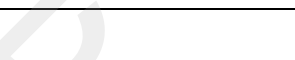 & $\alpha$ & $\beta$ & $\overline{\mathbf{R}^{2}}$ \\
\hline Pure systems & 1817 & $\begin{array}{l}\text { Training phase } \\
\text { Validation phase } \\
\text { Test phase } \\
\text { Total }\end{array}$ & $\begin{array}{l}1.000 \\
1.000 \\
0.990 \\
1.000\end{array}$ & $\begin{array}{l}0.00120 \\
0.00120 \\
0.00030 \\
0.00096\end{array}$ & $\begin{array}{l}0.99667 \\
0.99539 \\
0.9944 \\
0.99615\end{array}$ \\
\hline Binary systems & 794 & $\begin{array}{l}\text { Training phase } \\
\text { Validation phase } \\
\text { Test phase } \\
\text { Total }\end{array}$ & $\begin{array}{l}1.000 \\
1.000 \\
1.000 \\
1.000\end{array}$ & $\begin{array}{c}0.00120 \\
0.00094 \\
0.00130 \\
-0.00120\end{array}$ & $\begin{array}{l}0.99810 \\
0.99790 \\
0.99780 \\
0.99800\end{array}$ \\
\hline Ternary systems & 616 & $\begin{array}{l}\text { Training phase } \\
\text { Validation phase } \\
\text { Test phase } \\
\text { Total }\end{array}$ & $\begin{array}{l}1.000 \\
1.000 \\
1.000 \\
1.000\end{array}$ & $\begin{array}{l}0.0001100 \\
0.0001700 \\
0.0002900 \\
0.0000064\end{array}$ & $\begin{array}{l}0.99810 \\
0.99910 \\
0.99880 \\
0.99830\end{array}$ \\
\hline Global systems (RN1) & 3227 & $\begin{array}{l}\text { Training phase } \\
\text { Validation phase } \\
\text { Test phase } \\
\text { Total }\end{array}$ & $\begin{array}{l}1.000 \\
1.000 \\
1.000 \\
1.000\end{array}$ & $\begin{array}{l}0.00054 \\
0.00067 \\
0.00071 \\
0.00058\end{array}$ & $\begin{array}{l}0.99668 \\
0.99641 \\
0.99690 \\
0.99667\end{array}$ \\
\hline
\end{tabular}


Table 11

The values of the different errors of this study

\begin{tabular}{|l|l|l|l|l|l|l|}
\hline \multicolumn{1}{|c|}{ Systems } & RMSE & MSE & AAD & AARD\% & SSE & R $^{2}{ }_{\text {Cal }}$ \\
\hline Pure systems & 0.0027 & 0.0000 & 0.0024 & 07.6812 & 0.0244 & 0.9977 \\
\hline Binary systems & 0.0030 & 0.0000 & 0.0020 & 07.4144 & 0.0074 & 0.9988 \\
\hline Ternary systems & 0.0023 & 0.0000 & 0.0013 & 04.8599 & 0.0033 & 0.9989 \\
\hline Global system(RN1) & 0.0036 & 0.0000 & 0.0023 & 08.1295 & 0.0411 & 0.9980 \\
\hline
\end{tabular}

Table 12

Linear regression vectors and error performance between models obtained byRN1, RN2, RN3

\begin{tabular}{|l|l|c|c|c|c|c|c|c|c|}
\hline & $\boldsymbol{\alpha}$ & $\boldsymbol{\beta}$ & $\mathbf{R}^{2} \mathbf{e x p}$ & $\mathbf{R M S E}$ & $\mathbf{M S E}$ & $\mathbf{A A D}$ & AARD\% & SSE & $\mathbf{R}^{2}$ cal \\
\hline RN1 & 01.000 & 0.00058 & 0.99667 & 0.0036 & 0.0000 & 0.0023 & 08.1295 & 0.0411 & 0.9980 \\
\hline RN2 & 01.000 & -0.00082 & 0.99805 & 0.0027 & 0.0000 & 0.0018 & 05.2531 & 0.0237 & 0.9988 \\
\hline RN3 & $\mathbf{0 1 . 0 0 0}$ & $\mathbf{- 0 . 0 0 3 3 0}$ & $\mathbf{0 . 9 9 6 8 3}$ & $\mathbf{0 . 0 0 3 5}$ & $\mathbf{0 . 0 0 0 0}$ & $\mathbf{0 . 0 0 2 3}$ & $\mathbf{0 7 . 7 5 1 6}$ & $\mathbf{0 . 0 3 9 3}$ & $\mathbf{0 . 9 9 8 1}$ \\
\hline
\end{tabular}

Table 13

Sources and ranges of new data base for pure systems.

\begin{tabular}{|c|c|c|c|c|c|c|}
\hline $\begin{array}{l}\text { Pure } \\
\text { Systems }\end{array}$ & $\mathrm{T}(\mathrm{K})$ & P(Mpa) & $X_{i}=1$ & $\mathbf{K}\left(\mathbf{W} \cdot \mathbf{m}^{-1} \mathbf{K}^{-1}\right)$ & $\mathbf{N}$ & Reference \\
\hline \multirow{5}{*}{ R22 } & $298.15-393.15$ & $0.1-5.76$ & 1 & $0.0106-0.0682$ & 130 & [69] \\
\hline & 252.48-333.32 & 0 1-26.58 & 1 & $0.0667-0.1141$ & 37 & [43] \\
\hline & $223.15-323.15$ & $2.1-20.1$ & 1 & $0.0713-0.1262$ & 50 & [57] \\
\hline & $303-463$ & 0.1 & 1 & 0.01089-0.02064 & 05 & [45] \\
\hline & 208.56-289.6 & 0.9 & 1 & $0.0875-0.1222$ & 16 & [58] \\
\hline \multirow{5}{*}{ R142b } & 293.15-353.15 & $0.1-1.35$ & 1 & 0.0109-0.0165 & 21 & [37] \\
\hline & 302.201-304.346 & $1.6425-69.5827$ & 1 & 0.08064-0.11163 & 32 & [39] \\
\hline & 223.15-323.15 & $2.1-20.1$ & 1 & $0.0734-0.1183$ & 25 & [57] \\
\hline & $298-418$ & 0.1 & 1 & $0.01249-0.0214$ & 05 & [45] \\
\hline & 210.4-289.55 & 4.31-7.59 & 1 & $0.0872-0.1164$ & 07 & [58] \\
\hline R124 & $252.4-333.1$ & $0.62-18.67$ & 1 & $0.0584-0.0909$ & 35 & {$[52]$} \\
\hline
\end{tabular}

Table 14

Sources and ranges of new data base for binary systems

\begin{tabular}{|l|l|l|l|l|l|l|}
\hline $\begin{array}{l}\text { Binary } \\
\text { Systems }\end{array}$ & $\mathbf{T}(\mathbf{K})$ & $\mathbf{P}(\mathbf{M p a})$ & $\mathbf{X}_{\mathbf{i}}+\mathbf{X}_{\mathbf{J}}=\mathbf{1}$ & $\mathbf{K}\left(\mathbf{W} \cdot \mathbf{m}^{-{ }^{-1} \mathbf{K}^{\mathbf{1}} \mathbf{)}}\right.$ & $\mathbf{N}$ & Reference \\
\hline R22+R142b & $223.15-323.15$ & $2.1-20.1$ & $0.2796-0.729$ & $0.01664-0.1207$ & 75 & {$[57]$} \\
& $164.77-295.76$ & $2.7-8.14$ & $0.377-0.765$ & $0.0854-0.1422$ & 16 & {$[58]$} \\
\hline R22+R152a & $223.15-323.15$ & $2.1-20.1$ & $0.2488-0.750 !$ & $0.0759-0.1391$ & 75 & {$[57]$} \\
R22+R152a & $176.6-297.45$ & $2.44-8.02$ & $0.269-0.765$ & $0.0916-0.1512$ & 13 & {$[58]$} \\
R415 & $308.22-415.55$ & $0.12-1.684$ & $0.5+0.5=1$ & $0.0139-0.0225$ & 61 & {$[70]$} \\
\hline
\end{tabular}


Table 15

Sources and ranges of new data base for ternary systems

\begin{tabular}{|l|l|l|l|c|c|c|}
\hline $\begin{array}{l}\text { Ternary } \\
\text { Systems }\end{array}$ & $\mathbf{T ~ ( K )}$ & $\mathbf{P}(\mathbf{M p a})$ & $\mathbf{X}_{\mathbf{i}}+\mathbf{X}_{\mathbf{J}}+\mathbf{X}_{\mathbf{k}}=\mathbf{1}$ & $\mathbf{K}\left(\mathbf{W} \cdot \mathbf{~ m}^{-1} \mathbf{K}^{-1}\right)$ & $\mathbf{N}$ & Reference \\
\hline R409 & $305.67-427.13$ & $0.0591-1.364$ & $0.15+0.25+0.6=1$ & $0.0118-0.0196$ & 57 & {$[71]$} \\
\hline
\end{tabular}

N: Number of experimental data; R415 (R22, R152a: 50\%, 50\%); R409 (R142b, R124, R22: 15\%, 25\%, $60 \%)$.

Table 16

Comparison between the prediction model of different results of new data base (DB2) obtained by each model RN1, RN2, RN3

\begin{tabular}{|l|l|c|c|c|c|c|c|c|}
\hline Model & Systems & $\mathbf{N}$ & $\mathbf{R M S E}$ & $\mathbf{M S E}$ & $\mathbf{A A D}$ & $\mathbf{A R D \%}$ & SSE & $\mathbf{R}^{2}$ Cal \\
\hline \multirow{5}{*}{ RN1 } & Pure & 363 & 0.0284 & 0.0008 & 0.0212 & 48.7426 & 0.2925 & 0.8446 \\
\cline { 2 - 9 } & Binary & 240 & 0.0116 & 0.0002 & 0.0094 & 21.046 & 0.0486 & 0.9754 \\
\cline { 2 - 9 } & Ternary & 57 & 0.0304 & 0.0009 & 0.0202 & 115.911 & 0.0525 & -2.7634 \\
\cline { 2 - 9 } & Total & $\mathbf{6 6 0}$ & $\mathbf{0 . 0 2 4 4}$ & $\mathbf{0 . 0 0 0 6}$ & $\mathbf{0 . 0 1 6 9}$ & $\mathbf{4 4 . 7 1 1 5}$ & $\mathbf{0 . 3 9 3 6}$ & $\mathbf{0 . 8 9 8 2}$ \\
\hline \multirow{5}{*}{ RN2 } & Pure & 363 & 0.0218 & 0.0005 & 0.0147 & 23.0868 & 0.1723 & 0.9084 \\
\cline { 2 - 9 } & Binary & 240 & 0.0167 & 0.0004 & 0.0121 & 23.2145 & 0.1017 & 0.9484 \\
\cline { 2 - 9 } & Ternary & 57 & 0.0021 & 0.0000 & 0.0017 & 10.8684 & 0.0002 & 0.9827 \\
\cline { 2 - 9 } & Total & $\mathbf{6 6 0}$ & $\mathbf{0 . 0 2 0 4}$ & $\mathbf{0 . 0 0 0 4}$ & $\mathbf{0 . 0 1 2 6}$ & $\mathbf{2 2 . 0 7 8 0}$ & $\mathbf{0 . 2 7 4 3}$ & $\mathbf{0 . 9 2 9 1}$ \\
\hline \multirow{5}{*}{ RN3 } & Pure & 363 & 0.0140 & 0.0002 & 0.0108 & 21.1563 & 0.0710 & 0.9623 \\
\cline { 2 - 8 } & Binary & 240 & 0.0090 & 0.0001 & 0.0092 & 14.6979 & 0.0292 & 0.9853 \\
\cline { 2 - 8 } & Ternary & 57 & 0.0020 & 0.0000 & 0.0017 & 10.8850 & 0.0002 & 0.9832 \\
\cline { 2 - 8 } & Total & $\mathbf{6 6 0}$ & $\mathbf{0 . 0 1 2 3}$ & $\mathbf{0 . 0 0 0 2}$ & $\mathbf{0 . 0 0 9 4}$ & $\mathbf{1 7 . 9 2 0 8}$ & $\mathbf{0 . 1 0 0 4}$ & $\mathbf{0 . 9 7 4 2}$ \\
\hline
\end{tabular}

Table 17

Statistical analyses of the error of the predicted results (RN4).

\begin{tabular}{|l|c|l|l|l|l|c|c|}
\hline System & $\mathbf{N}$ & MSE & MSE & AAD & AARD\% & SSE & $\mathbf{R}^{2}{ }_{\text {Cal }}$ \\
\hline DB1+DB2 & 3887 & 0.0028 & 0.0000 & 0.0018 & 5.78 & 0.0303 & 0.9988 \\
\hline
\end{tabular}




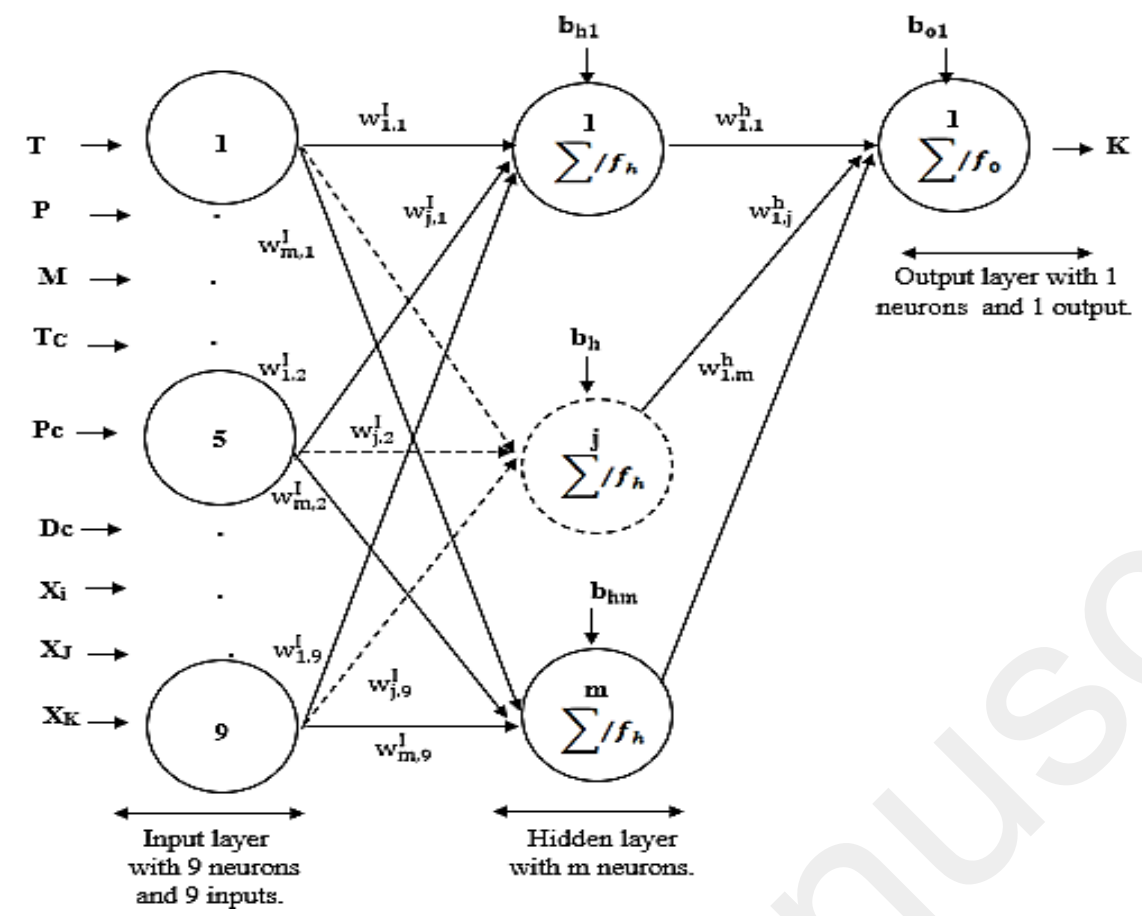

Fig.1.Feed forward neural network for the prediction of thermal conductivity of refrigerants. 


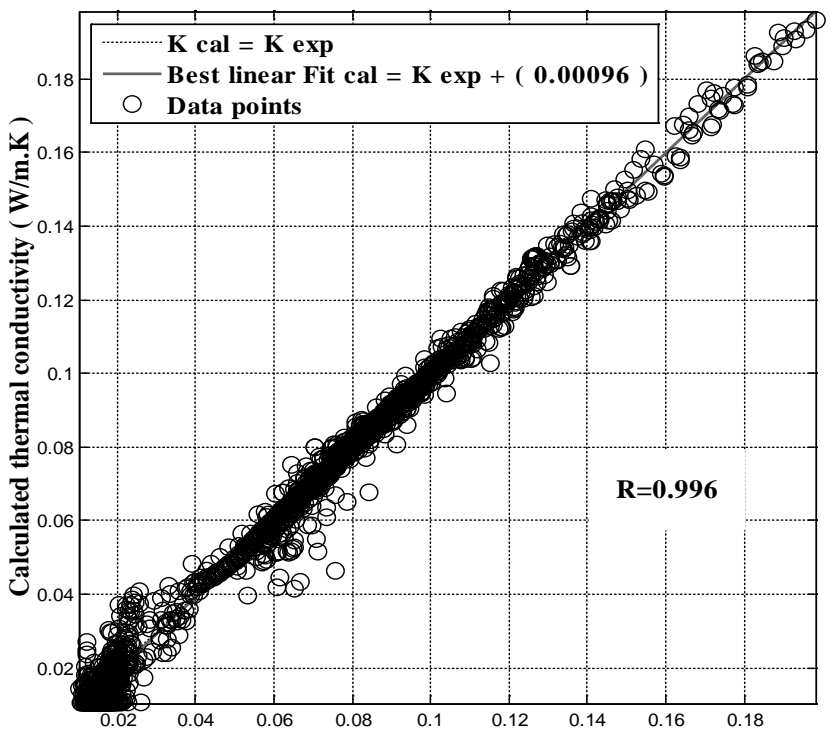

Experimental thermal conductivity ( W/m.K)

(a)

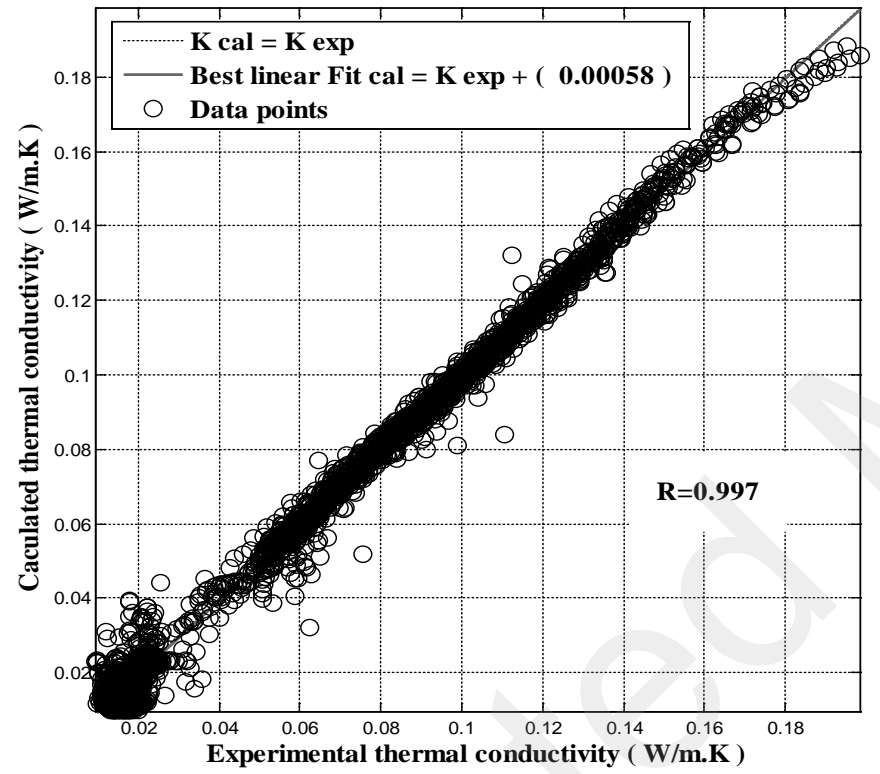

(c)

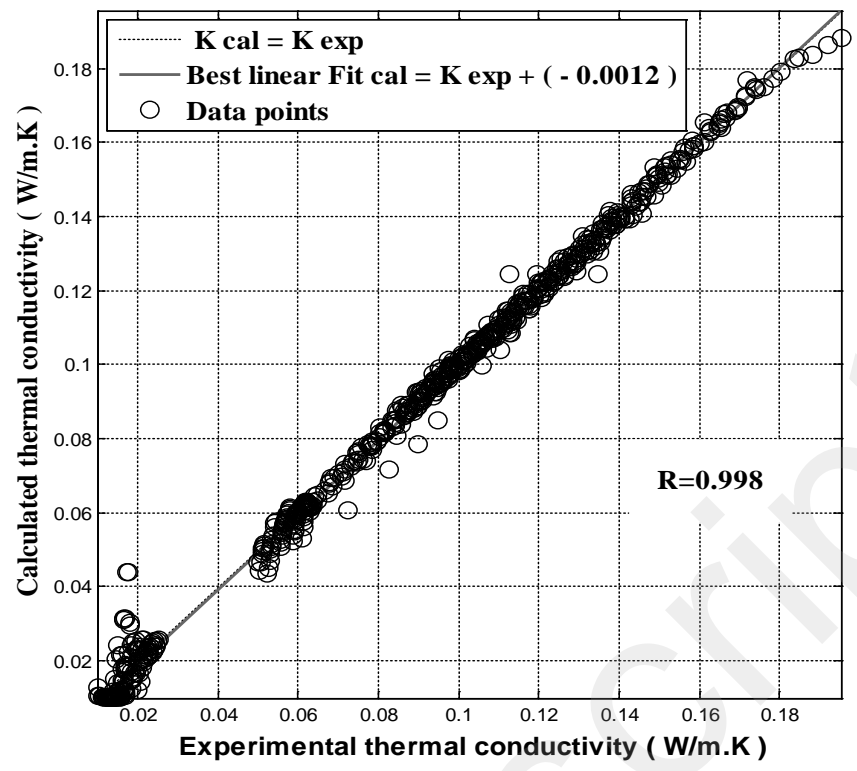

(b)

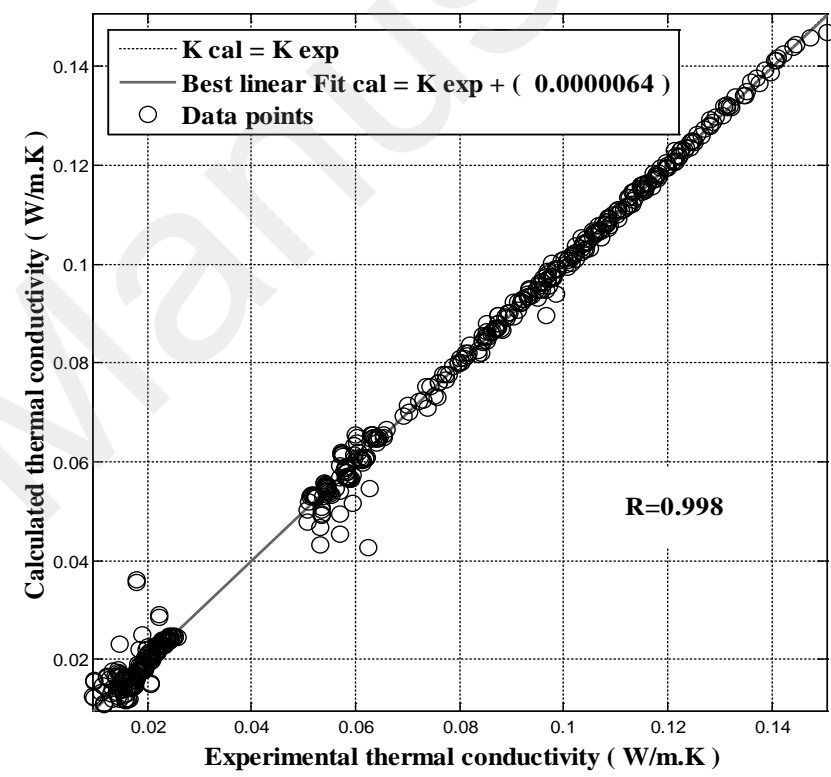

(d)

Fig. 2.Comparison of experimental and calculated values for the whole data set (a) Pure systems, (b) Binary systems, (c) Ternary systems, (d) Global system. 


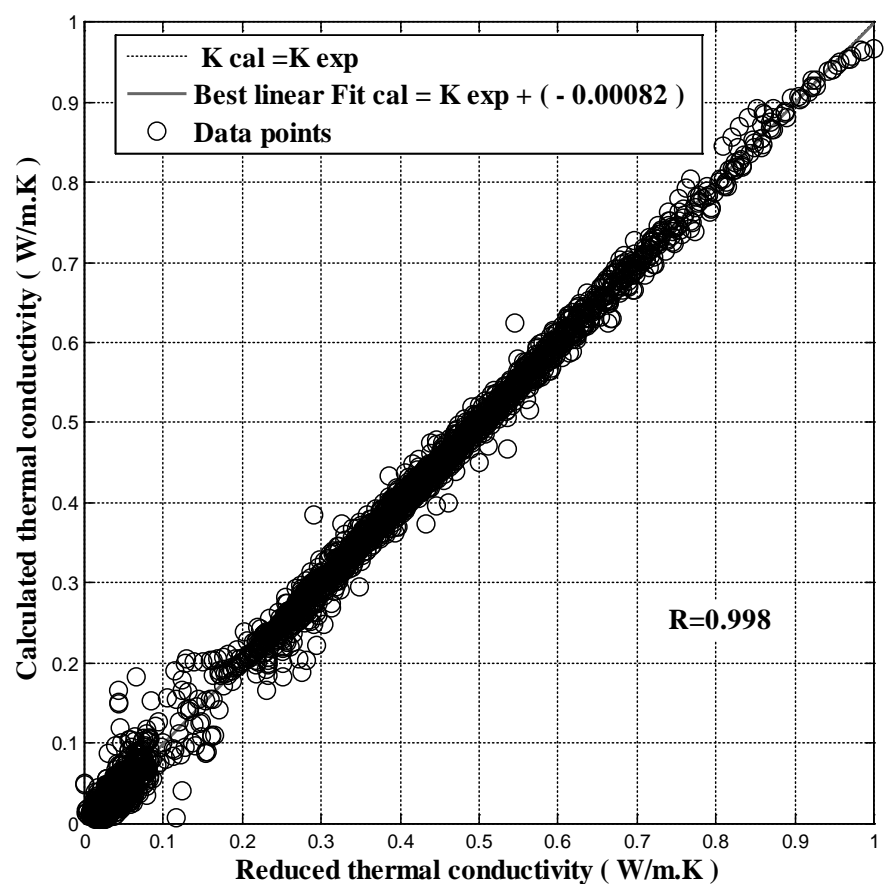

(e)

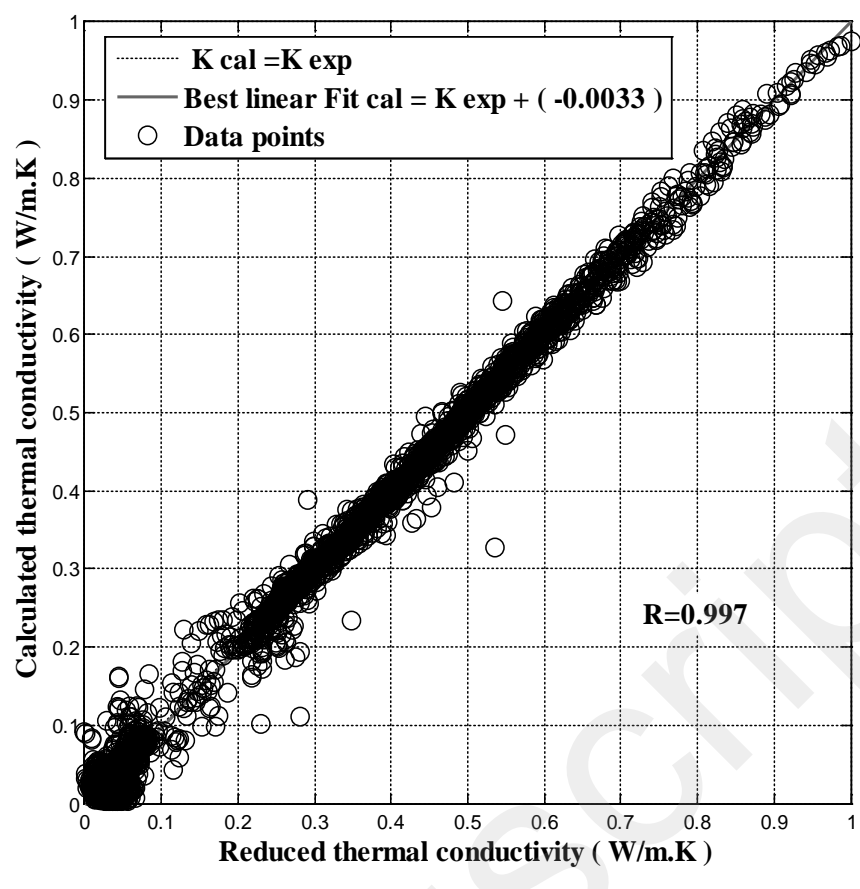

(f)

Fig. 3.Comparison of reduced and calculated values for the whole data set: (e) RN2 (number of neurons=17), (f) RN3 (number of neurons=13) for global system. 
(a)

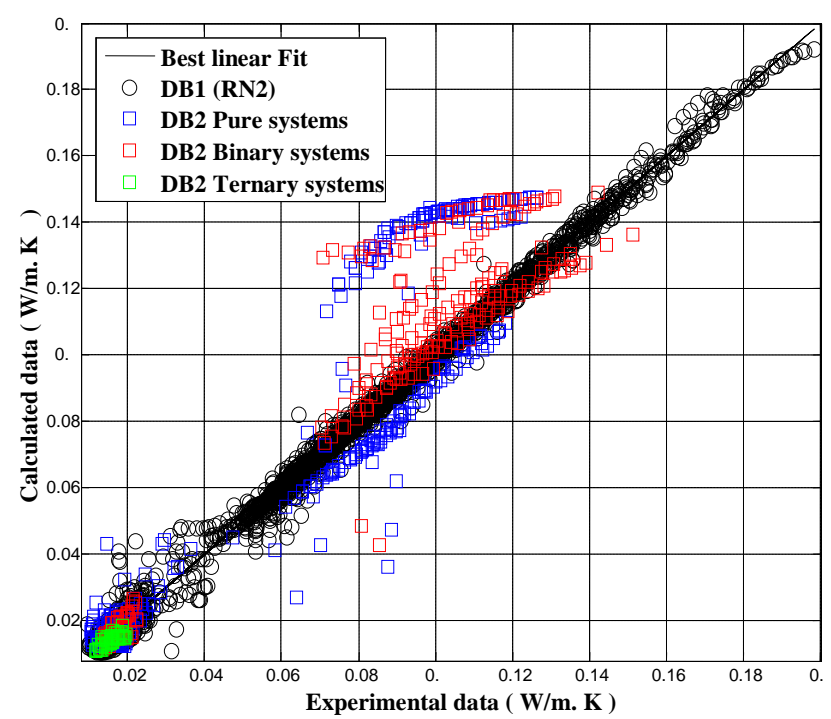

(c)

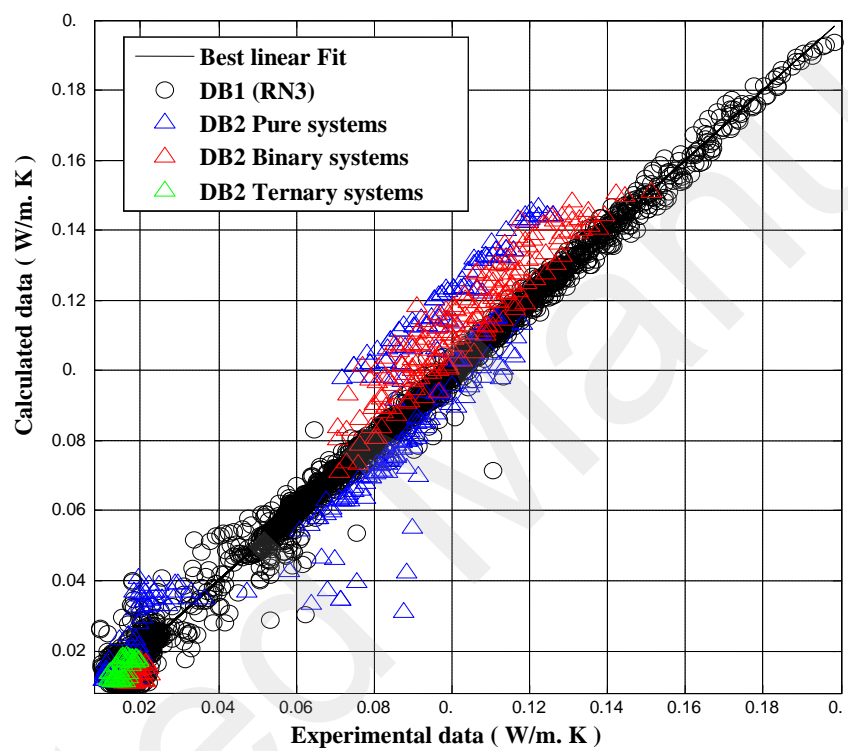

Fig.4.Comparison between data base DB1and DB2 for pure, binary and ternary systems:(a) RN1, (b) RN2, (c), RN3, for the prediction model. 


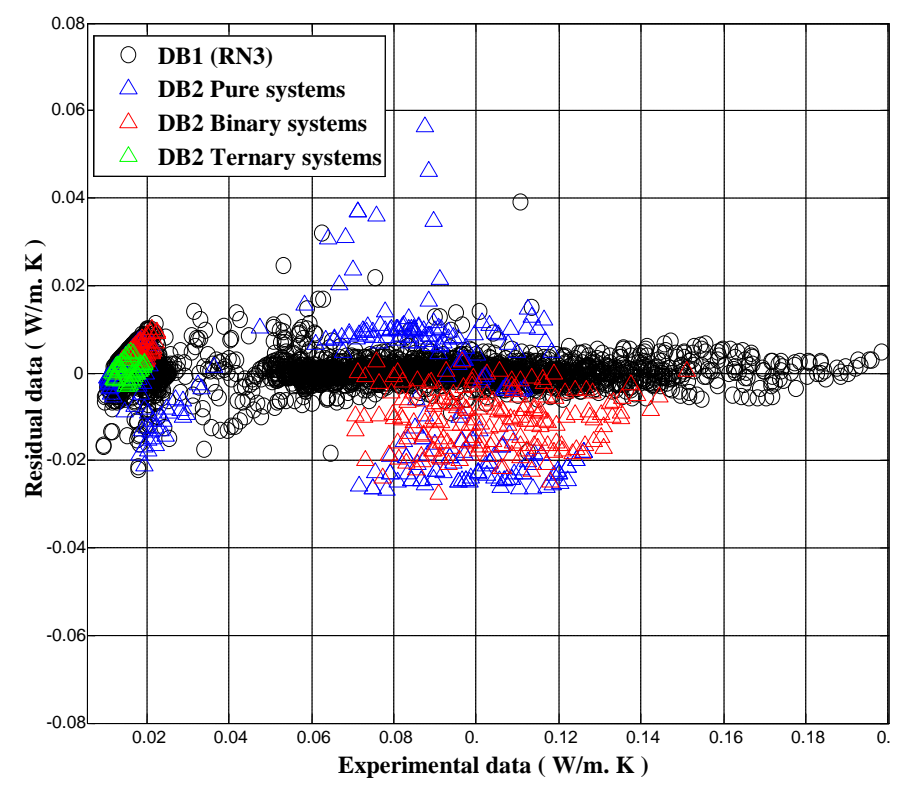

Fig.5.Plot of the residuals for calculated values ofthermalconductivity from the ANN model versus their experimentalvalues for DB2, [Residual $\left.=K_{\text {exp }, i}-K_{\text {cal, }, i}\right]$.

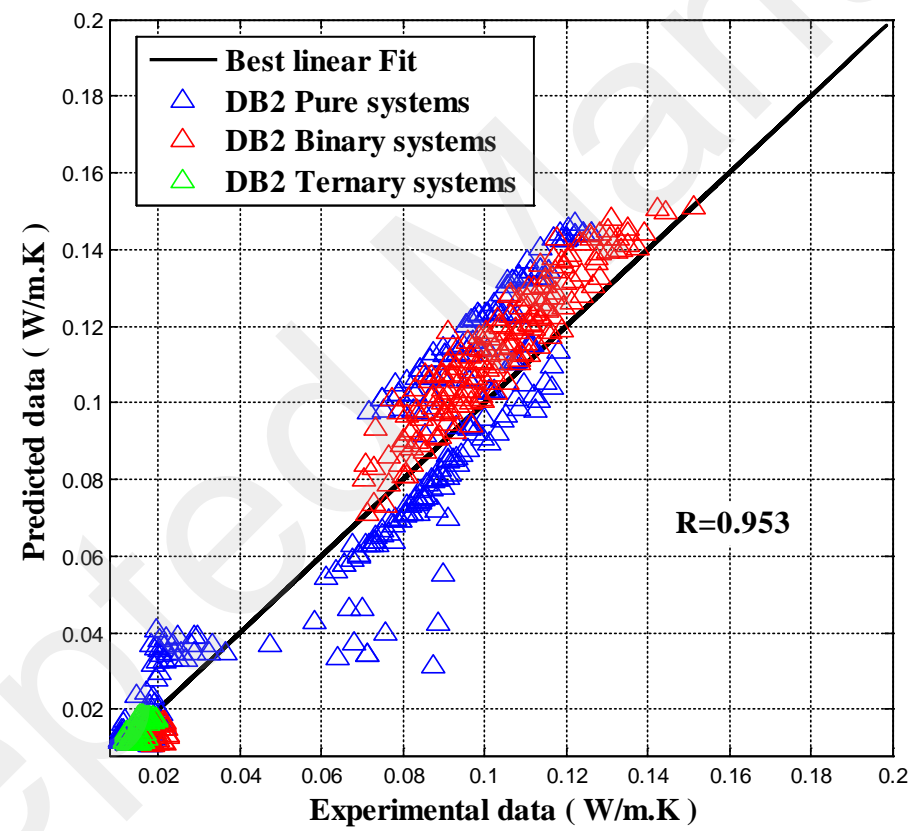

Fig.6.Prediction of the new data base DB2. 


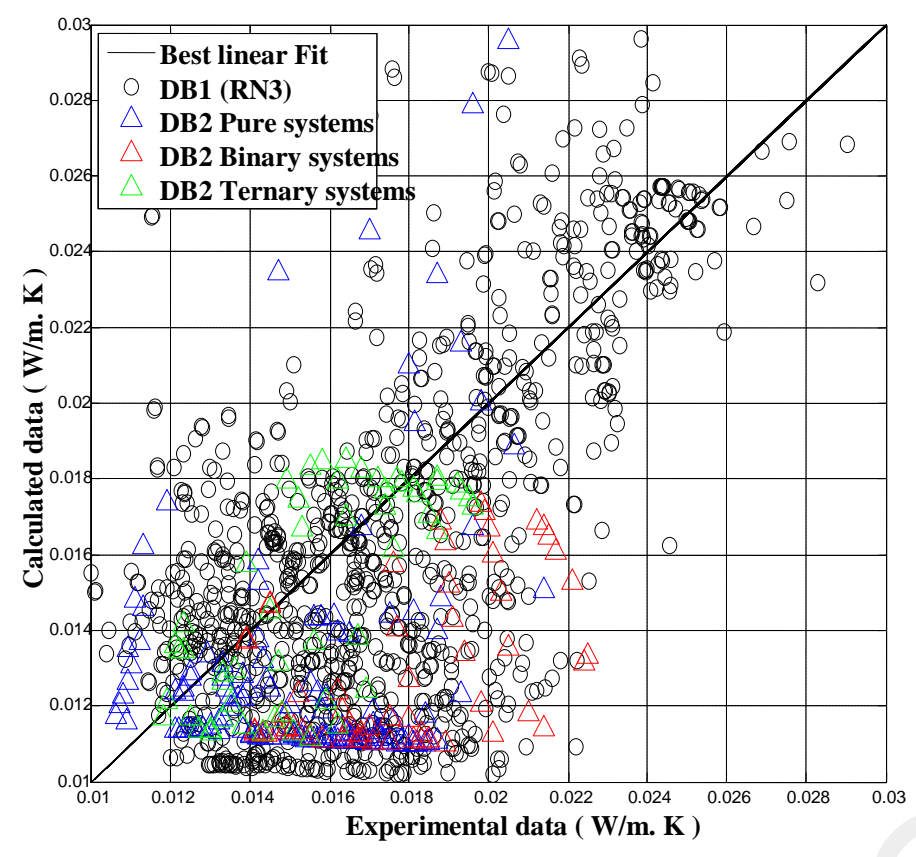

Fig. 7.The prediction between the DB2 and the actual data base DB1 in the range [0.01, 0.03].

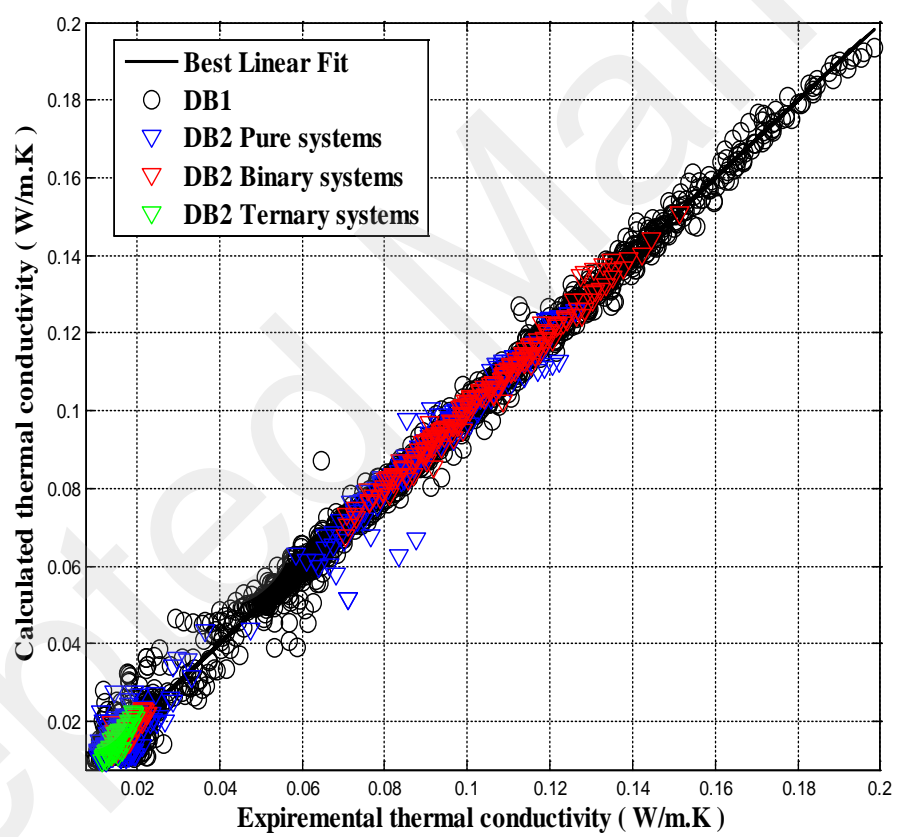

Fig. 8.Regression analysis plot for the optimal model between output and target of thermal conductivity(RN4). 


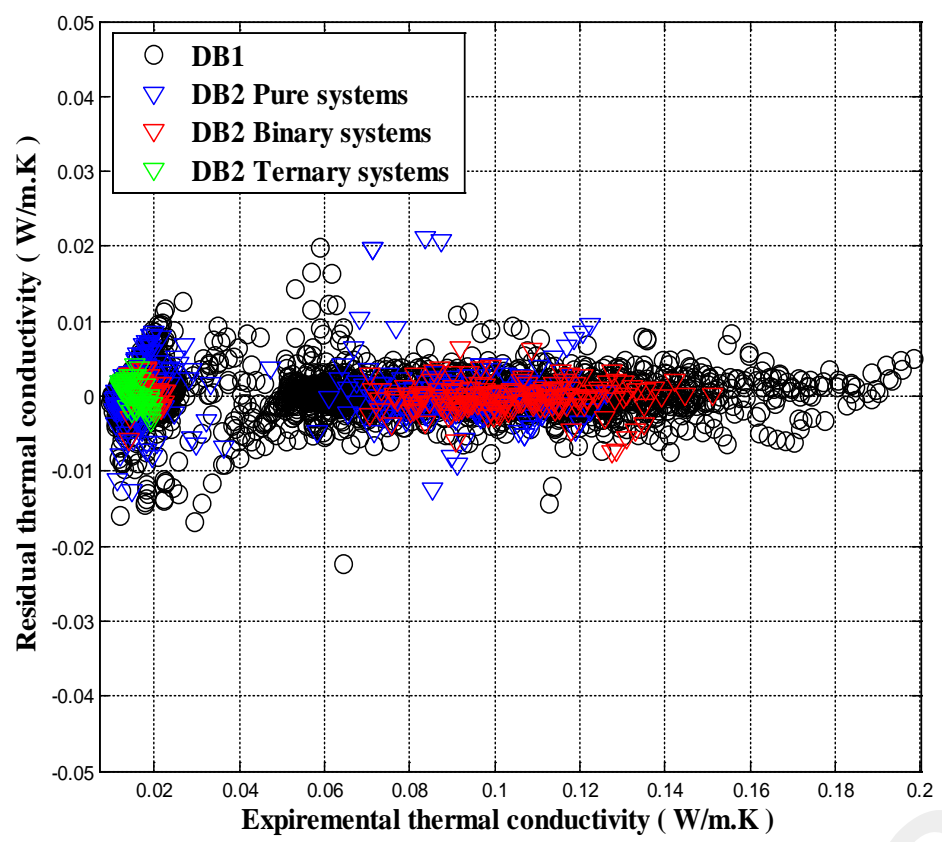

Fig. 9.Plot of the residuals for calculated values of thermal conductivity from the ANN model and their experimental data points (RN4). 